Document downloaded from:

http://hdl.handle.net/10251/117813

This paper must be cited as:

Pereiro-Barceló, J.; Bonet Senach, JL.; Goméz-Portillo, S.; Castro-Bugallo, MC. (2018). Ductility of high-performance concrete and very-high-performance concrete elements with $\mathrm{Ni}$-Ti reinforcements. Construction and Building Materials. 175:531-551. https://doi.org/10.1016/j.conbuildmat.2018.04.172

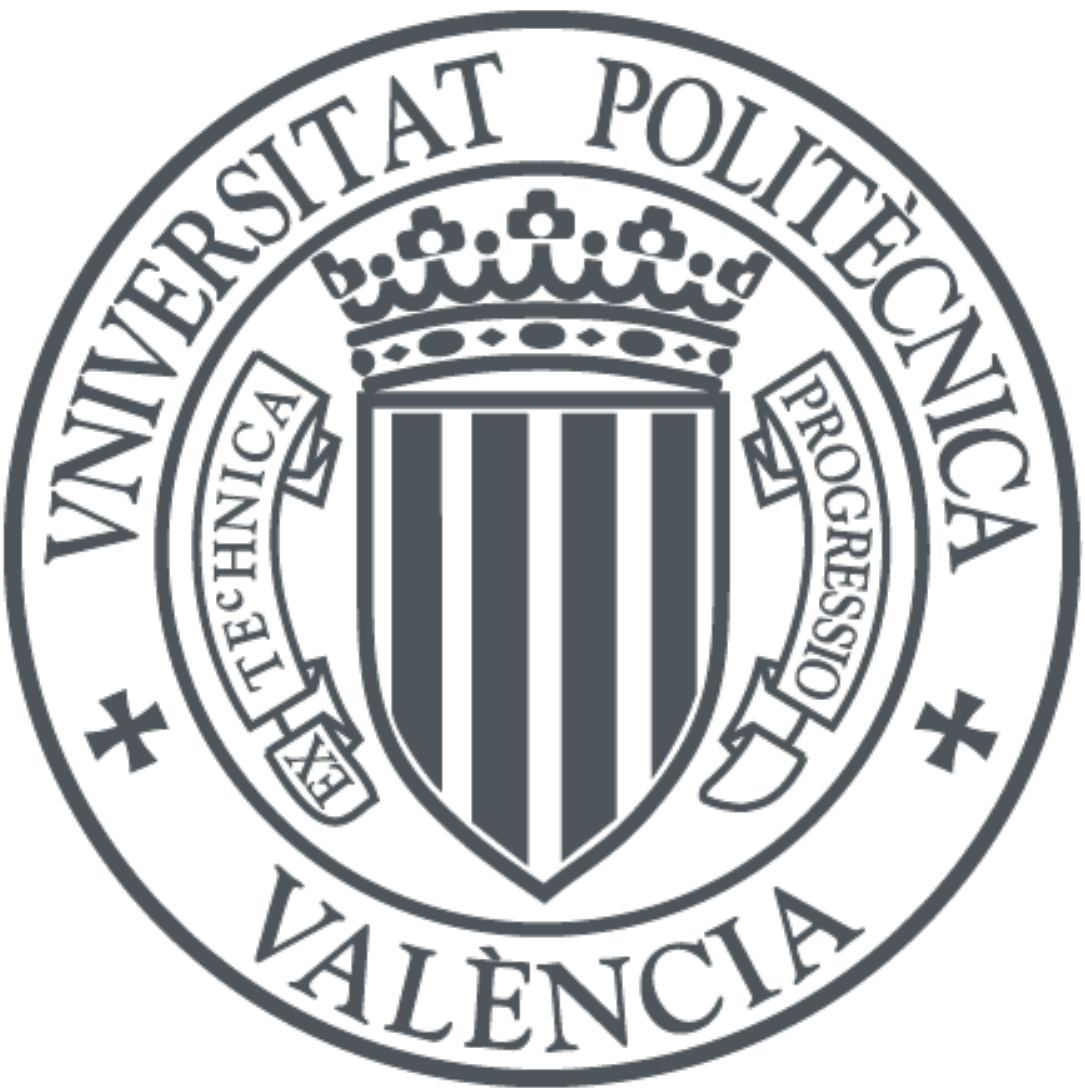

The final publication is available at

https://doi.org/10.1016/j.conbuildmat.2018.04.172

Copyright Elsevier

Additional Information 
Dear author,

Please note that changes made in the online proofing system will be added to the article before publication but are not reflected in this PDF.

We also ask that this file not be used for submitting corrections. 


\title{
Ductility of high-performance concrete and very-high-performance concrete elements with $\mathrm{Ni}$-Ti reinforcements
}

\author{
Javier Pereiro-Barceló ${ }^{a}$, José L. Bonet ${ }^{\mathrm{a}, *}$, Salvador Gómez-Portillo ${ }^{\mathrm{b}}$, Carmen Castro-Bugallo ${ }^{\mathrm{a}}$ \\ ${ }^{a}$ Construction Engineering and Civil Engineering Projects Department, ICITECH, Universitat Politècnica de València, C/Vera unnumbered, Valencia 46022, Spain \\ ${ }^{\mathrm{b}}$ Independent Civil Engineer, Universitat Politècnica de València, C/Vera unnumbered, Valencia 46022, Spain
}

\section{H I G H L I G H T S}

- Three VHPC and Ni-Ti and four HPC and Ni-Ti column were tested.

- A numerical model made in OpenSees was calibrated based on experimental data.

- A parametric study was conducted to study more variables beyond experimentation.

- Ductility and damage were higher in the HPC than in the VHPC specimens.

- Strength capacity was greater in the VHPC specimens.

\section{A R T I C L E I N F O}

\section{Article history:}

Received 15 January 2018

Received in revised form 12 April 2018

Accepted 21 April 2018

Available online $\mathrm{xxxx}$

\section{Keywords:}

High performance concrete

Very high performance concrete

Shape memory alloy

$\mathrm{Ni}$-Ti

Ductility

\begin{abstract}
A B S T R A C T
This article presents an experimental study on the behavior of high performance concrete (HPC) and very high performance concrete (VHPC) concrete columns with Nickel-Titanium (Ni-Ti) shape memory alloy (SMA) reinforcements in critical regions subjected to constant axial and lateral cyclic load combinations. These materials make the cast-in-place of concrete easier by reducing the amount of transverse reinforcement, improving performance, attenuating damage in critical regions, minimizing residual deformations and reducing repair costs in structures located in seismic areas. Seven experimental tests were carried out to analyze the behavior of this element type. A nonlinear static cyclic pushover analysis was performed with finite element software (OpenSees), whose results were compared with the experimental results. This analysis allowed a parametric analysis to be run to extrapolate the experimental results. Strength capacity was approximately $41.8 \%$ greater in absolute terms in the specimens manufactured with VHPC and $6.2 \%$ greater in adimensional terms in those manufactured with HPC. Displacement ductility was $34.0 \%$ higher in the HPC specimens, and lowered with relative normal force and with transverse reinforcement separation. A residual drift ratio below $0.70 \%$ was generally observed when specimens reached $20 \%$ strength capacity loss. The residual drift ratio increased as a result of progressive concrete cover degradation, especially in the specimens manufactured with HPC.
\end{abstract}

(c) 2018 Elsevier Ltd. All rights reserved.

\section{Introduction}

Currently, the criterion of capacity-based design [1-5] guarantees that plastic hinges appear in the beam ends. Thus, reinforced concrete columns have to provide a significant inelastic response with a minor decrease of load capacity without a significance loss of load capacity. To achieve this, previous codes [1-5] stipulates the necessary amount of transverse reinforcement. The amount

\footnotetext{
* Corresponding author.

E-mail addresses: japebar@upv.es (J. Pereiro-Barceló), jlbonet@cst.upv.es (J.L. Bonet), salgopor@cam.upv.es (S. Gómez-Portillo), macasbu@cst.upv.es (C. CastroBugallo).
}

of required transverse reinforcement is large when axial force is high according to these design codes. In addition, according to ACI Committee 441R-96 [6], reinforced concrete columns in moment-resisting frames constructed in areas of high seismicity should be proportioned to have adequate ductility because, despite the strong-column weak-beam concept in design, damage could occur at ends of the columns.

Another option to improve ductility is to add steel fibers in concrete [7-14]. These authors have verified that steel fibers helps increase total dissipated energy before failure, causes less damage and leads to greater deformation capacity under compressive axial loads, or even under axial loads with eccentricity. Recently, a special concrete with a high steel fibers content called Very-High- 
Performance Concrete (VHPC) was developed. The strength of this concrete ranges between 100 and $150 \mathrm{MPa}$ [15], shows high ductility on the post-peak branch under compression [16], develops high flexural tensile strength [15] and offers high strength and ductility under direct tension [15]. Another concrete that possesses high ductility is High-Performance Concrete (HPC), whose compressive strength ranges between 50 and $100 \mathrm{MPa}$, has a high metallic fibers content and it costs less than that of VHPC. In recent years, authors have conducted several researches to determine the behavior of HPC and VHPC beams subjected to bending [17-20] and torsion [21]. The use of these concretes for the strengthening of existing reinforced concrete beams also has been studied recently [22]. Regarding HPC and VHPC columns, the ductility and strength capacity of columns subjected to axial load [23,24] and to axial and cyclic lateral load $[25,26]$ is currently been investigated in the scientific literature.

In addition, Shape Memory Alloys (SMA) are another new material that is being increasingly used in the construction world [2729], more specifically the nickel and titanium (Ni-Ti) alloy. This material can be used in combination to the concrete to control the mechanical features of prestressed structural elements [3033], to obtain active confinement [34-36], to repair or to allow the self-repairing of concrete elements [37-39] and to improve the ductility of a structure [40-46]. The residual drifts that buildings undergo after earthquakes can be reduced thanks to the superelasticity (SE) of Ni-Ti. The use of these low-damage materials in structures (VHPC or HPC with SMA-SE bars) helps facilitate the cast-in-place of concrete, improve performance, minimize damage in critical regions, and reduce both residual deformations and repair costs in structures located in seismic zones [41].

Therefore, the objective of this article is to analyze the behavior of reinforced concrete supports manufactured with either VHPC or HPC and Ni-Ti reinforcements in the critical region of the support. Supports were subjected to both compressive axial force and cyclic lateral loading. Subsequently, a nonlinear static cyclic pushover analysis was carried out using the finite element software in OpenSees. The results were compared with the experimentally tested results. This analysis allowed a parametric analysis to be performed to extrapolate the experimental results.

\section{Experimental program}

\subsection{Specimens}

A test specimen was designed to model two semi-columns connected by an element (stub). The stub simulated the effect of an intermediate slab, beam or column-foundation joint. Fig. 1 shows the geometrical details. This specimen type has been used by Priestley and Park [47], Barrera et al. [48,49] and CaballeroMorrison et al. [12,13], among others.

Seven rectangular section supports $(260 \times 150 \mathrm{~mm})$ were manufactured and tested in the laboratory. The length of each halfcolumn $\left(L_{s}\right)$ was $1500 \mathrm{~mm}$. The shear slenderness ratio $\left(\lambda_{V}=L_{s} / \mathrm{h}\right.$, where $h$ is the total depth of the cross-section) was 5.77 in all the specimens. These supports were subjected to the combined efforts of constant axial and cyclic lateral load. In the connection zone, B-500SD bars were replaced with Ni-Ti bars, and were joined by shear screw coupler connectors. Ni-Ti bar length was $750 \mathrm{~mm}$, with a length of $150 \mathrm{~mm}$ inside the stub zone. The zone of the support where there were no Ni-Ti bars was reinforced with additional steel bars (16 mm diameter) to guarantee that failure would occur in the area with the Ni-Ti bars.

The parameters analyzed in the experimental study were: (a) concrete type (HPC or VHPC); (b) relative normal force $\left(v=N /\left[b \cdot h \cdot f_{c m}\right]\right.$, where $N$ was the axial load, $b$ was the cross- section width, and $f_{\mathrm{cm}}$ was the mean concrete compressive strength); (c) transverse reinforcement spacing. Three relative normal force levels were considered for the supports manufactured with HPC (0.10, 0.20 and 0.30), and two levels were contemplated for the supports manufactured with VHPC (0.10 and 0.20$)$. The minimum considered value equaled the minimum relative normal force to consider a structural element to be a column [3,5]. The maximum considered value was lower than the upper limits that could be applied to the columns subjected to seismic actions in accordance with EC-8 [3]. The upper limit choice was conditioned by the hydraulic actuator. Transverse reinforcement spacing was $100 \mathrm{~mm}$ and $250 \mathrm{~mm}$, which respectively equaled 8.33D and 20.83D, where $\mathrm{D}$ is the diameter of the longitudinal reinforcement that equaled $12 \mathrm{~mm}$. Transverse reinforcement separation was greater than the maximum spacing recommended to avoid local steel longitudinal reinforcement buckling in the concrete elements manufactured without steel fibers, as proposed by ACI-318 [5] (6D for special structures and 8D for ordinary structures), and by EC- 8 [3] (6D for high ductility (DCH) and $8 \mathrm{D}$ for medium ductility (DCM)). Nevertheless, these recommendations do not consider the favorable effect of the addition of steel fibers in concrete [11-13,50,51].

Table 1 provides details of the seven specimens. Specimen designation was carried out using $\mathrm{x}-\mathrm{VySz}$, where " $\mathrm{x}$ " is concrete type (VHPC or HPC), " $y$ " is relative normal force (V01 for $v=0.1$, V02 for $v=0.2$, V03 for $v=0.3$ ) and " $\mathrm{z}$ " is transversal reinforcement spacing ( 100 or $250 \mathrm{~mm}$ ).

A loading frame was used to run the tests (see Fig. 2a). The horizontal loading system comprised a $2500 \mathrm{kN}$ hydraulic actuator (Fig. 2b) which formed part of a frame. The lateral loading system was fixed to a frame to transmit lateral loads to the test slab (Fig. 2c). The lateral load was applied using a $500 \mathrm{kN}$ double effect hydraulic jack. For safety reasons, a system was designed to control the specimen's lateral instability in which steel bars were placed on both sides of the specimen and were fixed to another auxiliary frame (side bracing system).

\subsection{Material characterization}

Two concrete types, both self-compacting, were used for the seven tests: VHPC and HPC. VHPC had a nominal compressive strength in the cylindrical specimen $(300 \times 150 \mathrm{~mm})$ of $120 \mathrm{MPa}$, while concrete type HPC had a nominal resistance of $80 \mathrm{MPa}$. Cement type CEM I 42.5R-SR was used to manufacture VHPC and cement type CEM I 52.5R for the high-strength concrete. The amount of steel fibers employed in each concrete is displayed in Table 2. Dramix 80/30 BP fibers had hook ends, a length of $30 \mathrm{~cm}$ and a slenderness of 80 . Dramix $13 / 0.5$ had a straight geometry, a length of $13 \mathrm{~mm}$ and a slenderness of 26 .

The results of the mechanical characterization of the concrete are shown in Table 3 , where $f_{\mathrm{cm}}$ is the average compressive strength of the concrete (measured on $150 \times 300 \mathrm{~mm}$ cylinders [52]), $E_{c}$ is the elasticity modulus of the concrete, $f_{L O P}$ is the limit of proportionality in the flexural tensile strength test (measured on $550 \times 150 \times 500 \mathrm{~mm}$ prisms [53]), $f_{R, j}$ (for $\mathrm{j}=1-3$ ) corresponds to Crack Mouth Opening Displacements (CMOD) of 0.5, 1.5 and 2.5 mm respectively.

Regarding the characterization of the steel reinforcements, the results of the direct tensile characterization tests of the reinforcements [54] are shown in Fig. 3. The displayed values are the average of two characterization tests per diameter.

The Ni-Ti bars were $12 \mathrm{~mm}$ with a polished surface. By means of the differential scanning calorimetry (DSC) test, the four transformation temperatures $\left(A_{s}\right.$ and $A_{f}$ for the beginning and end of austenitic transformation, $M_{s}$ and $M_{f}$ for the beginning and end of 


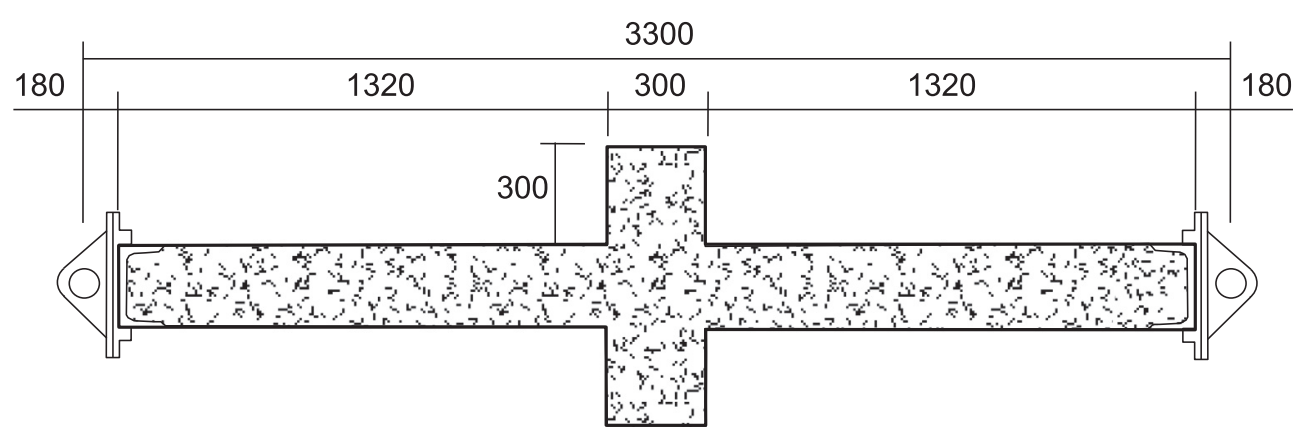

(a)

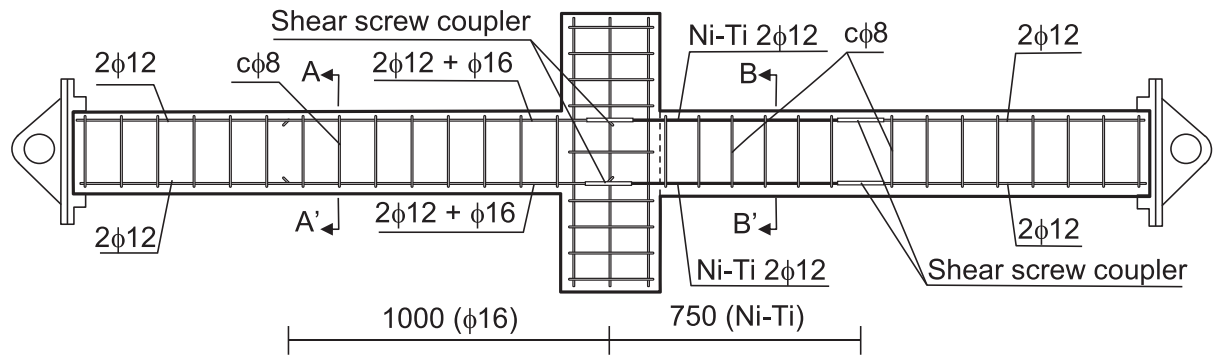

(b)

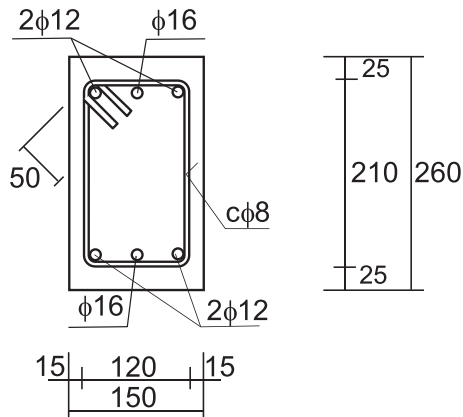

Section A-A'

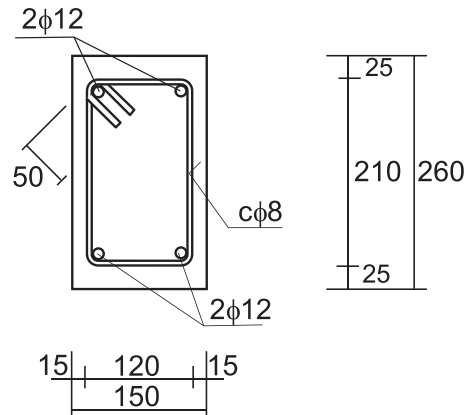

Section B-B'

(c)

Fig. 1. Specimen details (a) Dimensions (unit: mm); (b) Longitudinal reinforcement; (c) Cross-section details.

Table 1

Details of specimens.

\begin{tabular}{|c|c|c|c|c|c|c|c|}
\hline Id & Specimen & Concrete type & $\mathrm{h}(\mathrm{m})$ & $\lambda_{\mathrm{V}}$ & $\mathrm{N}(\mathrm{kN})$ & $v$ & $\mathrm{~s}_{\mathrm{t}}(\mathrm{mm})$ \\
\hline 1 & VHPC-V01S100 & VHPC & 0.26 & 5.77 & 497.68 & 0.10 & 100 \\
\hline 2 & VHPC-V02S100 & VHPC & 0.26 & 5.77 & 945.76 & 0.20 & 100 \\
\hline 3 & VHPC-V02S250 & VHPC & 0.26 & 5.77 & 940.17 & 0.20 & 250 \\
\hline 4 & HPC-V01S100 & HPC & 0.26 & 5.77 & 302.08 & 0.10 & 100 \\
\hline 5 & HPC-V02S 100 & $\mathrm{HPC}$ & 0.26 & 5.77 & 644.76 & 0.20 & 100 \\
\hline 6 & HPC-V02S250 & $\mathrm{HPC}$ & 0.26 & 5.77 & 655.84 & 0.20 & 250 \\
\hline 7 & HPC-V03S100 & $\mathrm{HPC}$ & 0.26 & 5.77 & 937.32 & 0.30 & 100 \\
\hline
\end{tabular}

martensitic transformation) were determined in accordance with Standard ASTM F2004-05 [55]: $M_{f}=-49.15^{\circ} \mathrm{C}, M_{s}=-31.23^{\circ} \mathrm{C}$, $A_{s}=-20.75^{\circ} \mathrm{C}$ and $A_{f}=-7.70^{\circ} \mathrm{C}$. Ni-Ti was also mechanically characterized by direct tensile tests. The test room temperature was 27-30 ${ }^{\circ} \mathrm{C}$. Austenitic modulus $E_{A}$ was $64647 \mathrm{MPa}$, Martensitic modulus $E_{M}$ was $2104 \mathrm{MPa}$, stress at the start of martensitic transformation was $450.21 \mathrm{MPa}$, and stress at the end of martensitic transformation was $609.83 \mathrm{MPa}$ for a strain of $65.6 \%$. The stressstrain curve of Ni-Ti is shown in Fig. 4.

\subsection{Instrumentation}

The instrumentation arranged in the specimens consisted of: strain gauges, thermocouples and displacement transductors. Strain gauges were used on the $\mathrm{Ni}$-Ti bars because they were located in the critical zone (Fig. 5). Thermocouples were also arranged on the Ni-Ti bars, one for each longitudinal bar (Fig. 5). Thermocouples were used to check if the temperature of the bar was approximately the temperature at which the mechanical characterization tests of Ni-Ti were conducted. This temperature was $27-30^{\circ} \mathrm{C}$. The test temperature and the characterization test tem-
209 


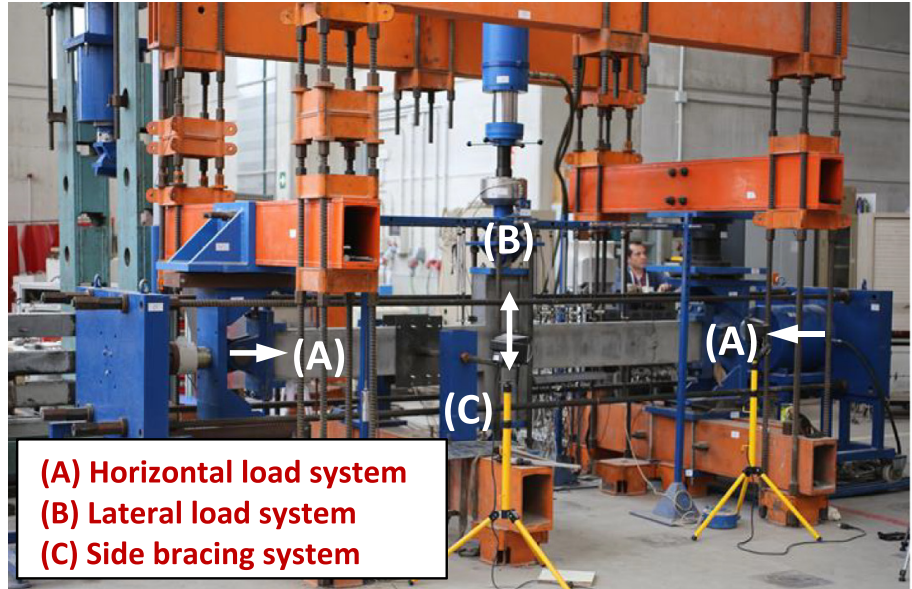

(a)

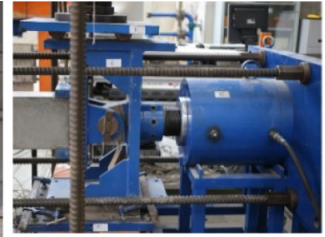

(b)

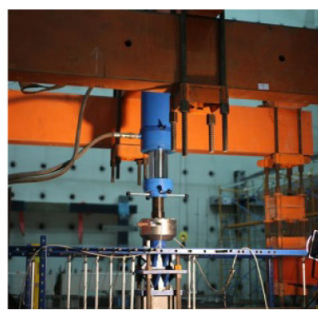

(c)

Fig. 2. Outer test configuration.

Table 2

Concrete doses $\left(\mathrm{kg} / \mathrm{m}^{3}\right)$.

\begin{tabular}{|c|c|c|}
\hline Description & VHPC & HPC \\
\hline Cement & 1000 & 525 \\
\hline Water & 177 & 196 \\
\hline Gravel ( $\left.D_{\max } 6 \mathrm{~mm}\right)$ & - & 450 \\
\hline Sand $\left(D_{\max } 4 \mathrm{~mm}\right)$ & - & 1045 \\
\hline Sand $\left(D_{\max } 0.8 \mathrm{~mm}\right)$ AF_T_0/8_S & 575 & - \\
\hline Sand ( $D_{\max } 0.4 \mathrm{~mm}$ ) AF_T_0/4_S & 310 & - \\
\hline Lime-stone filler & - & 200 \\
\hline Silica fume & 150 & - \\
\hline Steel fibers DRAMIX 80/30 BP & 60 (0.38\% vol.) & 80 (0.5\% vol. $)$ \\
\hline Steel fibers DRAMIX 13/0.5 & 90 (0.56\% vol.) & - \\
\hline Super-plasticizer & 29 & 8.13 \\
\hline
\end{tabular}

${ }^{* *} \mathrm{D}_{\max }$ : Maximum aggregate size.

perature were in this range. Therefore, the constitutive stressstrain curve obtained from characterization test was straightaway valid to simulate the specimens.

There were 24 displacement transductors in all, 13 in vertically positioned to acquire both the deformed shape and rotation of the stub, 10 horizontally placed to measure curvatures and one laid perpendicular to the specimen plane to control specimen buckling (see Fig. 5 and Fig. 6). A synchronized recording system was used where each photogram was assigned with the corresponding applied load.

\subsection{Test procedure}

All the specimens were tested 28 days after manufacture. The test room temperature was $27-30^{\circ} \mathrm{C}$. First, the axial load was applied. This load was kept constant along the test. Then, the lateral load was applied with a displacement control and a constant speed of $0.2 \pm 0.05 \mathrm{~mm} / \mathrm{min}$. The test sequence of the displacement controlled cycles was expressed in drift ratio $\left(\Delta / L_{s}\right)$ terms. For each drift ratio, three complete cycles were applied (Fig. 7) as defined in ACI 374.1 [56], FEMA-356 [57] and FEMA-P-750 [58]. The drift ratio $\Delta / L_{s}$ was obtained as a quotient between the displacement at the end of column $\Delta$ and the length of half-column $L_{s}$. Fig. 8 shows how to calculate the displacement at the end of column $\Delta$, where $\delta$ is the measurement registered by LVDT 9 and photogrammetry.

The expressions of Fig. 8 were used to calculate de bending moment in the critical section. The critical section was obtained according to Section 3.1 of manuscript. The rotation of the slab $\theta$ was computed by using the LVDTs 9 and 10 displayed in Fig. 5. In order to calculate the curvature in every instant, horizontal LVDTs were employed Fig. 6: the mean curvature between the consecutive horizontal LVDTs is computed.

\section{Test results and observations}

Fig. 9 and Fig. 10 show the experimental lateral load $V$ of the specimen ( $V=F_{v} / 2$ according to Fig. 8) and the drift ratio results for the specimens manufactured with VHPC and HPC. On these curves, cycles are represented by a continuous black line until a $20 \%$ specimen loss strength is achieved, while a continuous gray line is used for the other cycles. The limit value that corresponds to the $20 \%$ strength capacity loss $\left(0.8 \cdot V_{\max }\right.$ or $\left.0.8 \cdot V_{\min }\right)$ is indicated in the graphs. Fig. 11 and Fig. 12 show the total bending moment - average curvature at the critical section for the specimens manufactured with VHPC and HPC. The limit value that corresponds to the $20 \%$ strength capacity loss $\left(0.8 \cdot M_{\max }\right.$ or $\left.0.8 \cdot M_{\min }\right)$ is indicated in these graphs. The average curvature was obtained from the records of displacement transductors 15 and 16 (Fig. 6). Table 4 summarizes the main experimental results.

Table 3

Mechanical properties of concrete.

\begin{tabular}{|c|c|c|c|c|c|c|}
\hline Specimen & $\mathrm{f}_{\mathrm{cm}}(\mathrm{MPa})$ & $\mathrm{E}_{\mathrm{c}}(\mathrm{MPa})$ & $\mathrm{f}_{\mathrm{LOP}}(\mathrm{MPa})$ & $\mathrm{f}_{\mathrm{R}, 1}(\mathrm{MPa})$ & $\mathrm{f}_{\mathrm{R}, 2}(\mathrm{MPa})$ & $\mathrm{f}_{\mathrm{R}, 3}(\mathrm{MPa})$ \\
\hline VHPC-V01S100 & 123.46 & 44415 & 11.30 & 19.06 & 17.54 & 12.85 \\
\hline VHPC-V02S100 & 118.78 & 47905 & 11.84 & 19.83 & 18.06 & 14.01 \\
\hline VHPC-V02S250 & 119.06 & 44366 & 10.04 & 17.51 & 16.70 & 13.85 \\
\hline HPC-V01S100 & 75.03 & 35778 & 7.01 & 13.26 & 14.02 & 12.67 \\
\hline HPC-V02S100 & 81.31 & 36234 & 7.82 & 15.17 & 16.27 & 14.21 \\
\hline HPC-V02S200 & 84.00 & 36812 & 7.12 & 14.76 & 14.46 & 12.83 \\
\hline HPC-V03S100 & 79.07 & 35629 & 6.18 & 11.67 & 12.65 & 11.02 \\
\hline
\end{tabular}




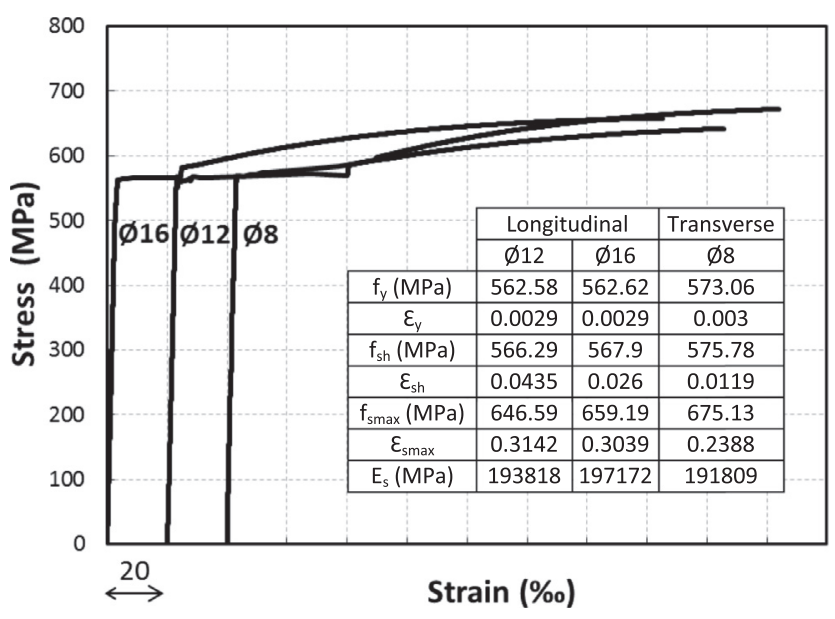

Fig. 3. Mechanical properties of reinforcements.

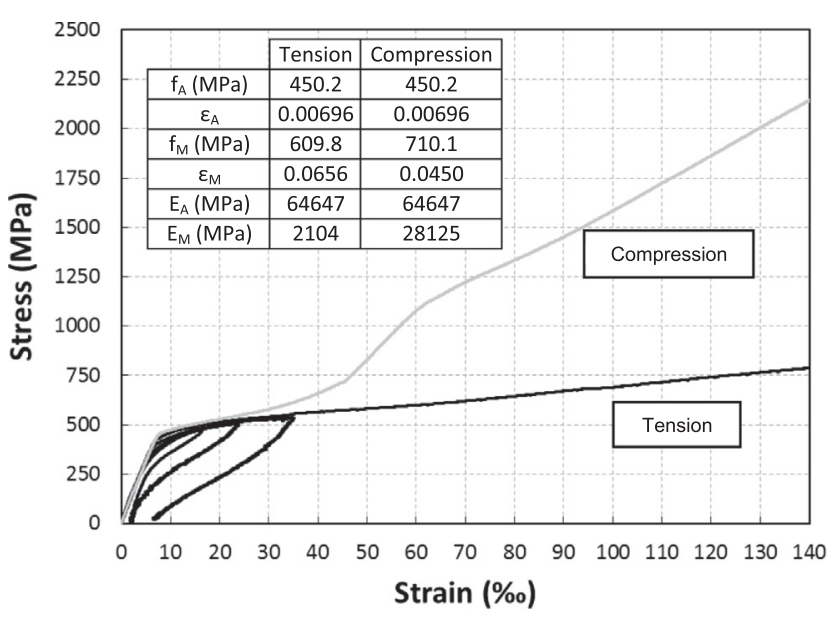

Fig. 4. Mechanical properties of Ni-Ti bars.

\subsection{General behavior}

The following observations were made:

1. In general, a multicracking network, which is hard to detect by the naked eye, was produced in the specimens manufactured with VHPC. Supports were painted with water-repellent varnish so that, once the test had finished, cracks were revealed when the area was soaked with water (Fig. 13c). Cracking was well distributed for low loads in both specimens made with VHPC and HPC. VHPC specimens underwent more distributed crack pattern (more cracks with smaller width) than HPC specimens. A single major crack appeared when the plastic hinge was formed in both cases.

2. In general, the tests stopped when strength capacity loss exceeded 20\%. VHPC-V01S100 and HPC-V01S100 (specimens with the lowest normalized axial level) did not reach $20 \%$ loss of strength capacity before connector sliding took place.

3. The sliding of the connectors between the steel and SMA bars took place in specimens VHPC-V01S100, VHPC-V02S100 and HPC-V01S100. Specimen VHPC-V02S100 reached a 20\% loss of strength capacity before connector sliding occurred. Therefore, the obtained ductility is not affected by connector sliding.

4. No longitudinal reinforcement buckling took place in VHPC because the concrete cover gradually degraded in all cases and did not spall. The concrete cover underwent more damage in HPC specimens than in VHPC specimens (see Fig. 13 and Fig. 14). For this reason, the Ni-Ti bar buckling was observed in HPC specimens. Once the buckling occurred, the test was stopped.

5. When the maximum lateral load situation $\left(V_{\max }\right)$ was achieved, one main crack appeared where damage concentrated. The main crack was located $100 \mathrm{~mm}$ from the connection between the support and the stub in specimen VHPC-V01S100 (Fig. 13a). It was located on the connection in the supports in VHPC specimens with greater axial force (VHPC-V02S100 and VHPC-V02S250) (Fig. 13b and Fig. 13c). It was located between 70 and $100 \mathrm{~mm}$ from the stub in the specimens manufactured with HPC (Fig. 14).

6. On supports VHPC-V02S100 and VHPC-V02S250, the critical section was $20 \mathrm{~mm}$ from the stub, but was $70 \mathrm{~mm}$ from the stub in the other elements, according to the strain gauges and de physical observation, despite this section not being the one under the maximum bending moment. This is due to the confinement that the stub causes in the close sections [59] which led to an increase in the ultimate bending moment of the these sections.

7. The critical region length $l_{c r}$ was analyzed by the physical observation method [60]. The $l_{c r} / h$ ratio (being $h$ the total depth of the section) increased with relative normal force (Table 4). A similar result was obtained in all cases. The $l_{c r} / h$ ratio was between 0.46 and 0.54 , except for specimen HSC-V02S250 and it was 0.85 . This case coincided with the lower quality concrete (HPC) and the greater transversal reinforcement spacing.

\subsection{Strength and deformation capacity}

Table 4 reports the relative maximum lateral load $\left(V_{\max } /\left(f_{c m} \cdot b \cdot h\right)\right)$ and the relative maximum bending moment $\left(M_{\max } /\left(f_{c m} \cdot b \cdot h^{2}\right)\right)$, where $f_{c m}$ is the mean compressive strength of concrete. The relative bending moment was calculated in the critical section. Second-order effects were considered.

The envelopes of each loading direction were obtained from the lateral load-drift ratio (see Fig. 9 and Fig. 10) and the momentcurvature (see Fig. 11 and Fig. 12) responses. The average envelope was also obtained. To determine the deformation capacity of specimens, an idealized bilinear diagram of the experimental envelopes was used $[13,59,60]$. The diagram was formed by a growing elastic branch and a decreasing inelastic branch (Fig. 15). The elastic branch passed through the origin and the point that corresponded to $75 \%$ of the maximum load or moment and ended at the maximum lateral load or moment value. The decreasing inelastic branch began at the point at which the elastic branch finished, and then ended at the point defined by both the displacement (or curvature) for the $20 \%$ loss of strength capacity and the theoretical load obtained after performing the equality of the areas of the idealized and experimental curves.

Ultimate displacement ductility is defined as $\mu_{\Delta u}=\Delta_{u} / \Delta_{y I}$ where $\Delta_{u}$ is the ultimate displacement of the column that corresponds to $80 \%$ of the maximum load on the post-peak branch and $\Delta_{y I}$ is the effective elastic displacement. The ultimate curvature ductility is defined as $\mu_{\varphi u}=\varphi_{u} / \varphi_{y I}$ where $\varphi_{u}$ is the ultimate curvature of the section that corresponds to $80 \%$ of the maximum moment on the post-peak branch and $\varphi_{y l}$ is the effective elastic curvature.

Table 4 displays the ductility results. In general, 20\% maximum bending moment loss was not achieved in the moment-curvature diagram and, consequently, lower curvature ductility was obtained. The specimens with a relative normal force $v=0.20$ depicted higher curvature ductility $\left(\mu_{\varphi u}\right)$ than the expected value if the conservative expression that related both ductilities from 


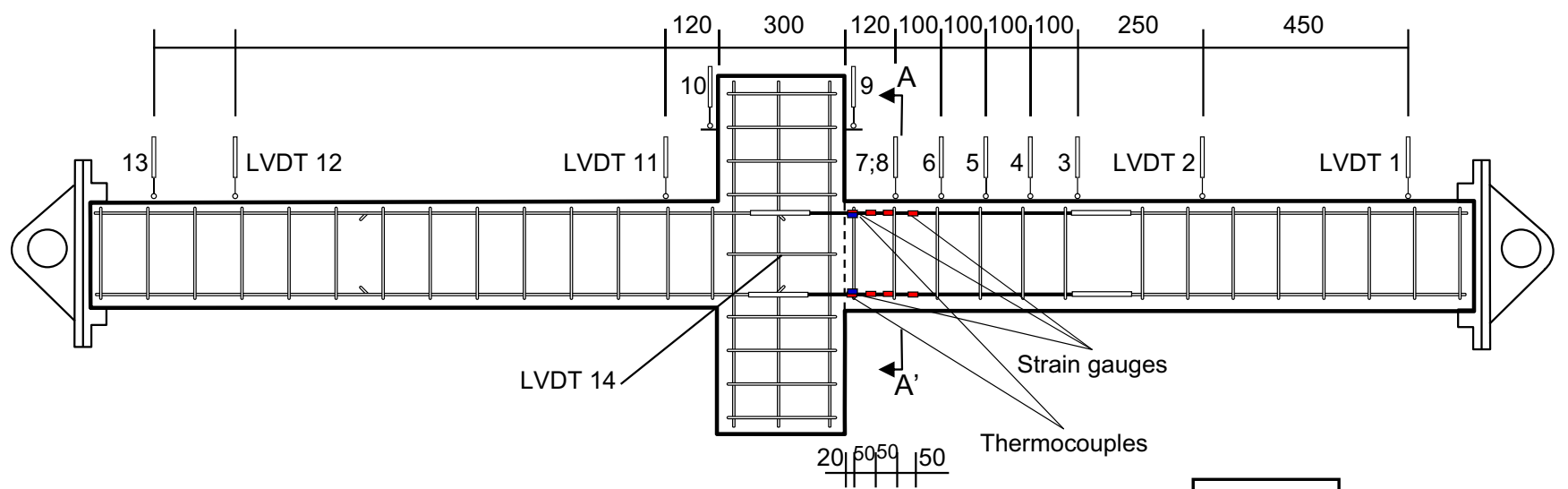

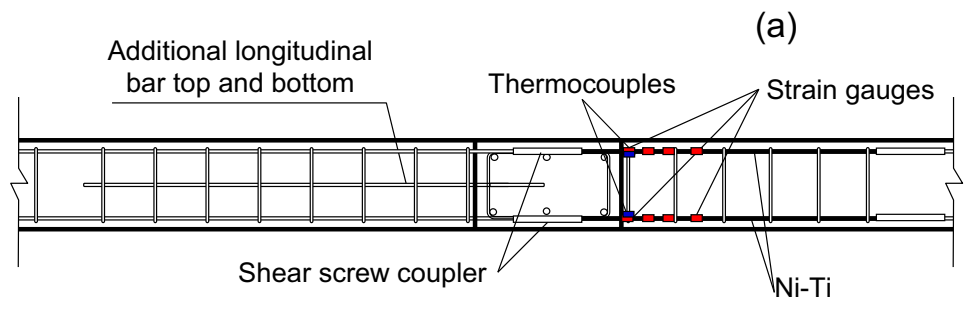

(b)

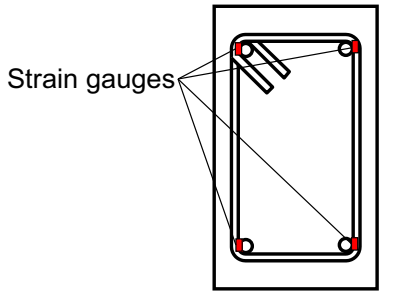

Section A-A'

(c)

Fig. 5. Vertical transductors and location of strain gauges and thermocouples (unit: $\mathrm{mm}$ ).
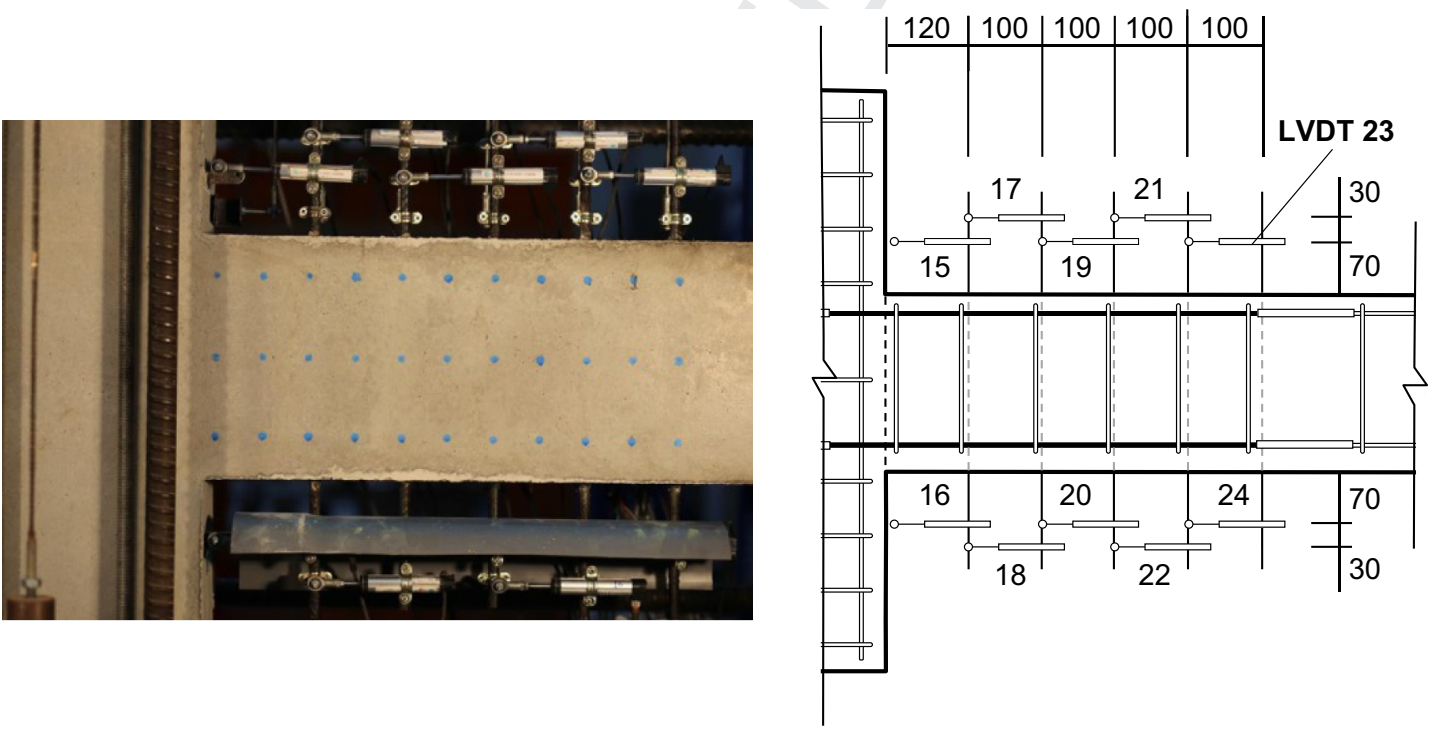

Fig. 6. Horizontal transductors (unit: $\mathrm{mm}$ ).

EC-8 [3] ( $\left.\mu_{\varphi u}=2 \mu_{\Delta u}-1\right)$ was considered. However, the specimens with an axial level $v=0.10$ and $v=0.30$ showed lower curvature ductility $\left(\mu_{\varphi u}\right)$ than expected because $20 \%$ maximum bending moment loss was far from being accomplished in specimen HPCV03S100 and connector sliding occurred in specimens VHPCV01S100 and HPC-V01S100 before 20\% maximum bending moment loss was reached; therefore, its plastic behavior could not be fully developed.

\subsection{Energy dissipation}

The energy dissipation that corresponded to the $j$ th cycle of the $i$ th drift ratio hysteretic loop is defined as follows (Fig. 16):

$E_{i}^{j}=\oint_{A}^{B} V d \Delta$

The total energy dissipated during the test is:

$E_{\text {sum }}=\sum_{i}^{m_{1}} \sum_{j}^{m_{2}} E_{i}^{j}$ 


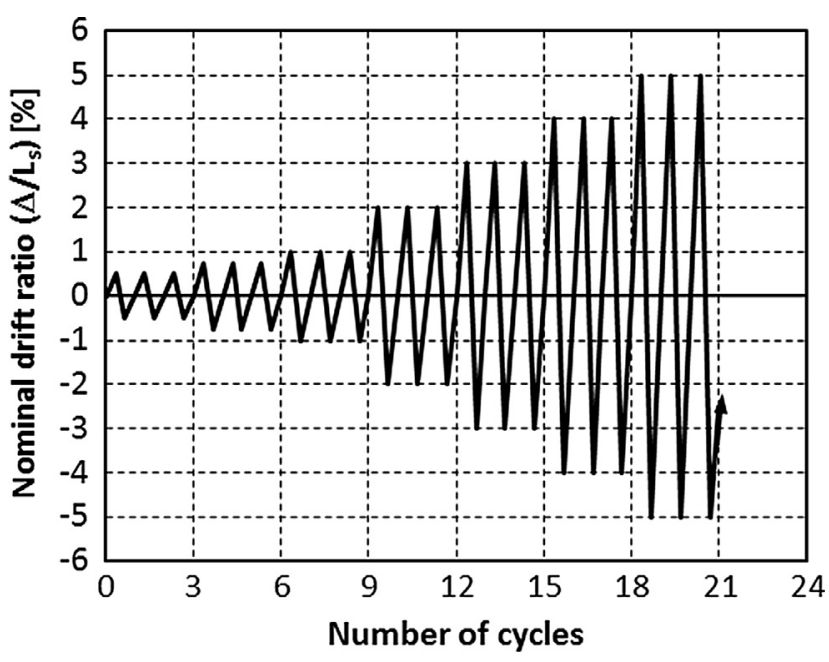

Fig. 7. Cyclic loading protocol.

where $E_{\text {sum }}$ is cumulate dissipated energy; $m_{1}$ is the number of the drift ratio up to failure; $m_{2}$ is the number of cycles for each drift ratio. In order to compare dissipated energy among specimens, normalized dissipated energy $E_{N}$ was calculated as [61]:

$E_{N}=\sum_{i}^{m_{1}} \sum_{j}^{m_{2}}\left[E_{i}^{j} /\left(V_{i}^{j} \Delta_{i}^{j}\right)\right]$

$\Delta_{i}^{j}=\left(\left|\Delta_{i}^{j+}\right|+\left|\Delta_{i}^{j-}\right|\right) / 2, V_{i}^{j}=\left(\left|V_{i}^{j+}\right|+\left|V_{i}^{j-}\right|\right) / 2$

where $\Delta_{i}^{j+}$ and $\Delta_{i}^{j-}$ are the maximum displacements that correspond to the cycle at the ith drift ratio in the pull and the push direction, respectively; $V_{i}^{j+}$ and $V_{i}^{j-}$ are the lateral load that correspond to $\Delta_{i}^{j+}$ and $\Delta_{i}^{j-}$, respectively. Table 4 shows the results of the total dissipated energy and the normalized dissipated energy of all the specimens.

\subsection{Stiffness degradation} [61]:

The stiffness $\left(K_{i}\right)$ of the column at the $i$ th drift ratio is defined as $K_{i}=\sum_{j=1}^{m_{2}} V_{i}^{j} / \sum_{j=1}^{m_{2}} \Delta_{i}^{j}$ where $K_{i}$ is the average secant stiffness at the $i$ th drift ratio level; $\Delta_{i}^{j}$ and $V_{i}^{j}$ are defined in Eq. (4). The normalized column stiffness was calculated by dividing the average secant stiffness $\left(K_{i}\right)$ by the stiffness at a drift ratio of $0.5 \%\left(K_{0}\right)$ to compare the results as the columns maintained an elastic behavior for this drift ratio.

$\eta_{K_{i}}=K_{i} / K_{0}$

Table 4 shows the stiffness results of each specimen for a drift ratio of $0.5 \%\left(K_{0}\right)$. Fig. 17 depicts the normalized stiffness degradation $\left(\eta_{K_{i}}\right)$ according to the ith drift ratio.

\subsection{Residual drift ratio}

The mean residual drift ratio $\left(D_{r, i}\right)$ of the column at the $i$ th drift ratio is defined as:

$D_{r, i}=\left(\left|D_{r, i}^{+}\right|+\left|D_{r, i}^{-}\right|\right) / 2$

$D_{r, i}^{+}=\sum_{j=1}^{m_{2}} D_{r, i j}^{+} / m_{2} ; D_{r, i}^{-}=\sum_{j=1}^{m_{2}} D_{r, j}^{-} / m_{2}$

where $D_{r, i}^{+}$and $D_{r, i}^{-}$are the average values of the residual drift ratios at the $i$ th drift ratio in the pull and the push direction, respectively; $D_{r, i j}^{+}$and $D_{r, i}^{-}$are the residual drift ratios of the $j$ th cycle at the $i$ th drift ratio in the pull and the push direction, respectively; $m_{2}$ is the number of cycles for each ith drift ratio.

Fig. 18 displays the mean residual ratio of the column at the $i$ th drift ratio for all the specimens. As observed, the mean residual drift ratio generally showed values below $0.70 \%$ for drift ratios lower than $3.5 \%(\Delta=52.5 \mathrm{~mm})$; for this drift ratio, displacement $\Delta$ was greater than the ultimate displacement $\left(\Delta_{\mathrm{u}}\right)$ of the specimens (see Table 4). Only two cases did not follow the previous trend: specimen HPC-V01S100, which obtained a final drift ratio of $4.5 \%$ with a residual drift of $1.5 \%$ due to the connector sliding; specimen HPC-V03S100, whose residual drift was $1.15 \%$ for a final drift of 3.3\%. In specimens VHPC-V01S100 and VHPC-V02S100 the residual drift ratio increased when the connector slipped. The residual drift ratio also increased as a result of progressive concrete cover degradation, especially in the HPC-V02S100 specimen in comparison to VHPC-V02S100 specimen. In this case, the increase of the residual drift is $31.5 \%$ for a drift ratio of 5 .

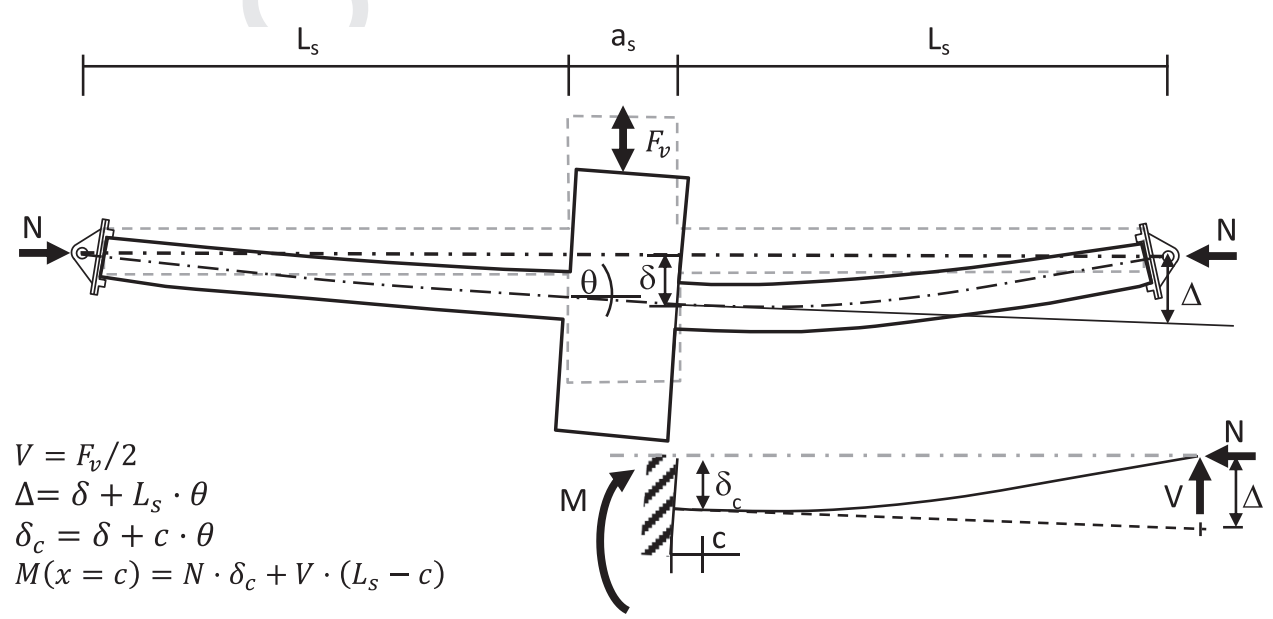

Fig. 8. Specimen idealization. 


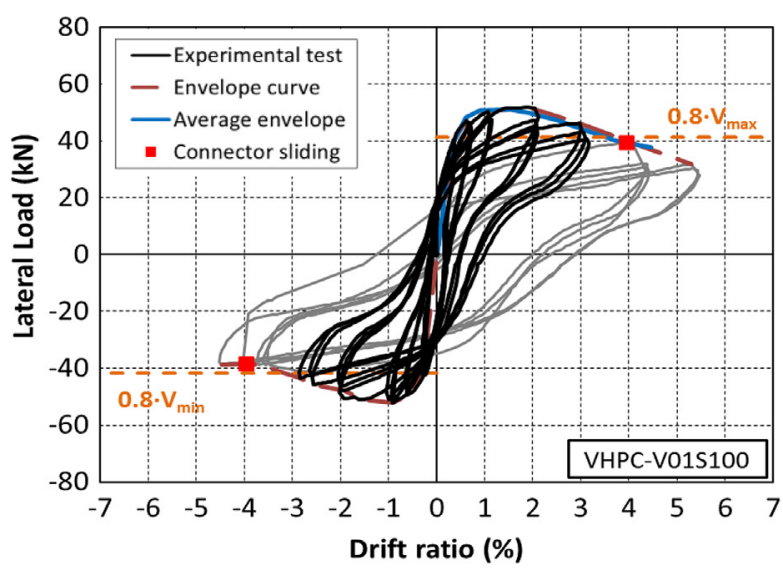

(a)

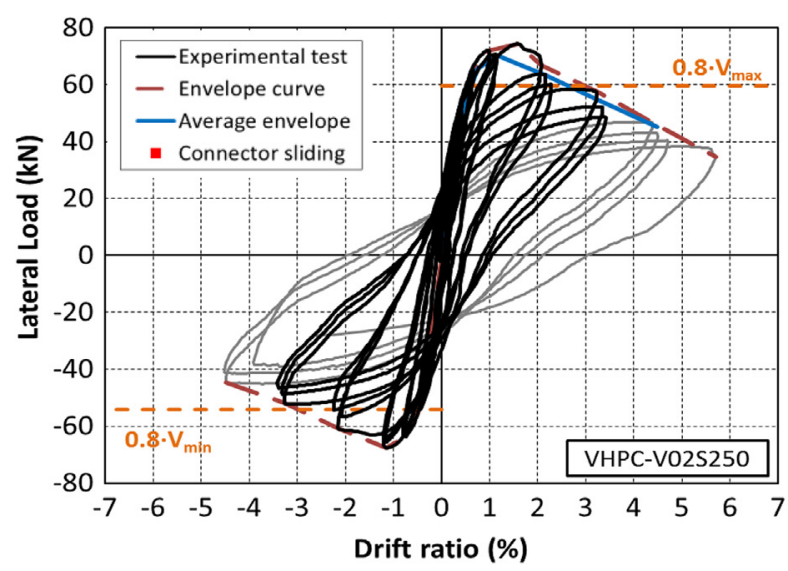

(c)

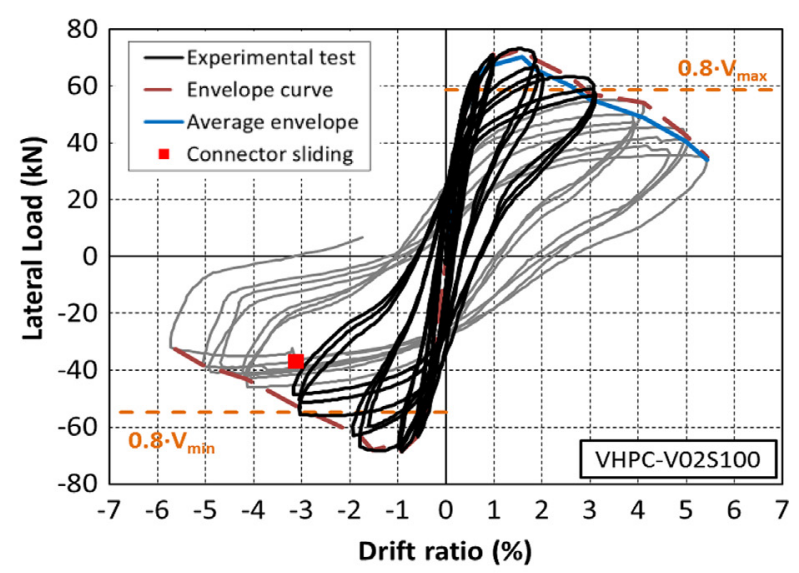

(b)

\subsection{Plastic hinge length}

It was assumed that the whole plastic behavior was developed due to bending in the plastic hinge. All the inelastic deformations of the support concentrated along the length of plastic hinge $l_{p}$. Ultimate displacement $\Delta_{u}$ can be calculated as:

$\Delta_{u}=\Delta_{y I}+\Delta_{p}$

where $\Delta_{p}$ is the plastic displacement that equals:

$\Delta_{p}=\left(\varphi_{u}-\varphi_{y I}\right) \cdot l_{p} \cdot\left(L_{s}-0.5 \cdot l_{p}\right)$

From Eq. (10) it is possible to obtain ratio $l_{p} / h$. Table 4 shows ratio $l_{p} / h$ obtained for each test.

\section{Analysis results}

\subsection{Effect of concrete type}

The effect of concrete type can be analyzed by comparing the following pairs of tests: VHPC-V01S100 vs. HPC-V01S100; VHPCV02S100 vs. HPC-V02S100; VHPC-V02S250 vs. HPC-V02S250. In these pairs of tests the separation between stirrups and the relative normal force remained constant.

Greater strength capacity $\left(V_{\max }\right.$ and $\left.M_{\max }\right)$ was accomplished in absolute terms in the specimens manufactured with VHPC. $V_{\max }$ was $42.7 \%$ and $M_{\max }$ was $40.9 \%$ higher on VHPC specimens than on HPC specimens. However, the increase in the strength capacity of a support manufactured with VHPC compared to one manufac- tured with HPC was not proportional to the increase in compressive strength from HPC to VHPC.

Displacement ductility (see $\mu_{\Delta u}$ in Table 4) decreased with concrete strength. On average the displacement ductility in the specimens manufactured with HPC was $34 \%$ greater than in the specimens manufactured with VHPC, but fiber content was double that in HPC. However, curvature ductility (see $\mu_{\varphi u}$ in Table 4) did not show a clear trend because it was not possible to achieve a $20 \%$ maximum moment loss in any case.

In general, the normalized dissipated energy (see $E_{N}$ in Table 4) in the specimens manufactured with VHPC was smaller than in the specimens manufactured with HPC, except when tie spacing was $250 \mathrm{~mm}$ (VHPC-V02S250 and HPC-V02S250). HPC specimens dissipated more energy at the expense of concrete damage.

Regarding the stiffness for a drift ratio of $0.5 \%$ (see $K_{0}$ in Table 4 ), as expected the specimens manufactured with VHPC were $38 \%$ stiffer on average. No significant differences in the stiffness degradation $\left(\eta_{K_{i}}\right)$ between the specimens manufactured with VHPC and HPC were observed (Fig. 17). The residual drift ratio $\left(D_{r, i}\right)$ was generally higher in the specimens manufactured with HPC due to concrete cover degradation (Fig. 18). This degradation occurred due to both the lower steel fibers content and the lesser concrete-fiber adhesion since strength was lower. The relative plastification length (see $l_{p} / h$ in Table 4 ) was longer in the specimens made with HPC (except for HPC-V02S100) because plastic displacement $\Delta_{p}$ was greater than in the VHPC specimens. 


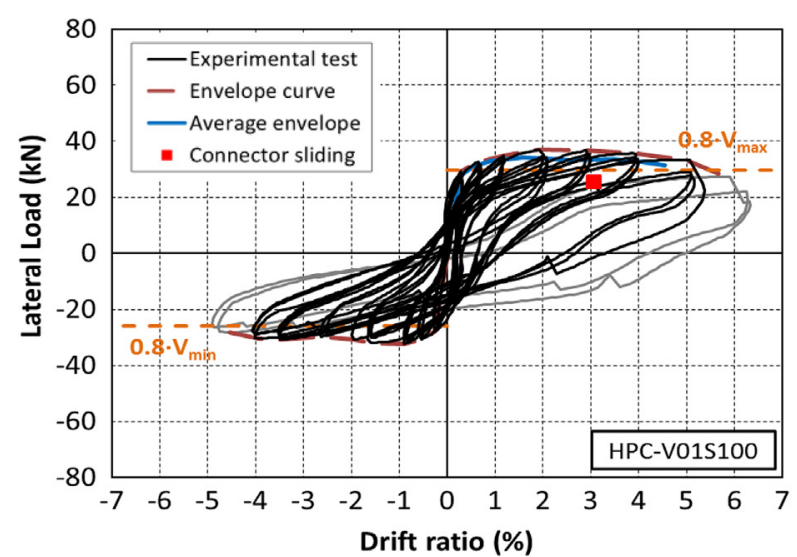

(a)

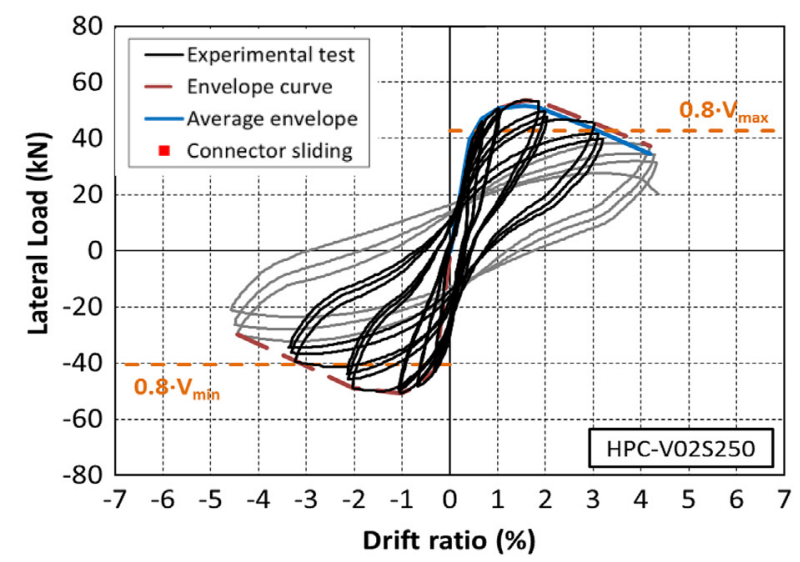

(c)

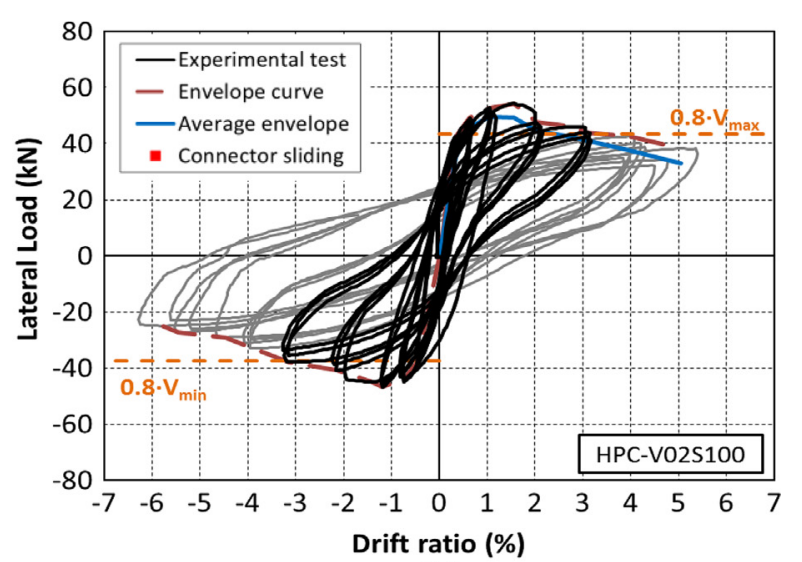

(b)

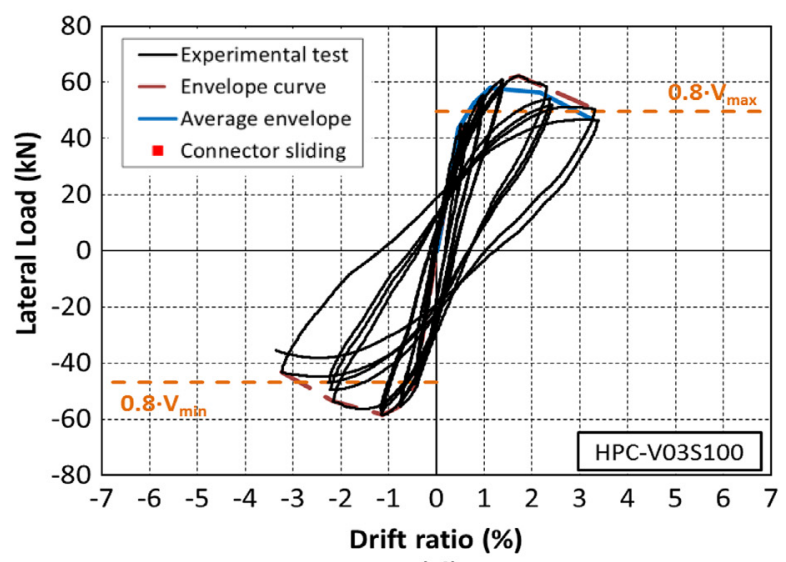

(d)

Fig. 10. Experimental lateral load-drift ratio curves for the HPC specimens.

\subsection{Effect of relative normal force}

The effect of relative normal force $(v)$ can be analyzed by comparing the following series of tests: VHPC-V01S100 vs. VHPCV02S100 and HPC-V01S100 vs. HPC-V02S100 vs. HPC-V03S100.

Regarding strength capacity $\left(V_{\max }\right.$ and $\left.M_{\max }\right)$, the higher the axial force, the greater strength capacity became.

As expected, displacement ductility (see $\mu_{\Delta u}$ in Table 4) reduced with axial force. However, curvature ductility (see $\mu_{\varphi u}$ in Table 4) did not show this tendency because $20 \%$ maximum moment loss was not achieved.

In general, the normalized dissipated energy (see $E_{N}$ in Table 4) reduced with axial force. The stiffness for a drift ratio of $0.5 \%$ (see $K_{0}$ in Table 4) increased with axial force. As Fig. 17 shows, the higher axial force, the greater stiffness degradation became $\left(\eta_{K_{i}}\right)$. No significant differences were observed for the residual drift ratio $\left(D_{r, i}\right)$ between the two specimens made of VHPC, while the residual drift ratio $\left(D_{r, i}\right)$ increased with axial force in the HPC specimens due to concrete cover degradation (Fig. 18). Finally, as expected, the relative plasticization length (see $l_{p} / h$ in Table 4 ) increased with the applied axial force.

\subsection{Effect of tie spacing}

The effect of transverse reinforcement spacing $\left(s_{t}\right)$ can be analyzed by comparing the following series of tests: VHPC-V02S100 vs. VHPC-V02S250 and HPC-V02S100 vs. HPC-V02S250.
As expected, strength capacity did not depend on transverse reinforcement separation. Both displacement ductility (see $\mu_{\Delta u}$ in Table 4) and curvature ductility (see $\mu_{\varphi u}$ in Table 4) reduced with tie separation since the specimen's level of confinement reduced. The normalized dissipated energy (see $E_{N}$ in Table 4) reduced with separation. No clear trend was seen regarding stiffness for a drift ratio of $0.5 \%$ (see $K_{0}$ in Table 4 ) and relative plasticization length (see $l_{p} / h$ in Table 4 ). No significant differences in both stiffness degradation $\left(\eta_{K_{i}}\right)$ (see Fig. 17) and the residual drift ratio $\left(D_{r, i}\right)$ (see Fig. 18) were observed among specimens with different tie separations.

\subsection{Bond of Ni-Ti bars}

The NiTi bars had polished surface. Studies conducted by Mo and Chan (1996) [62] and Verderame et al. (2009) [63] show that the bond of this type of bars is reduced by more than $70 \%$. In addition, the bond is further reduced in the case of cyclical loads. Nevertheless, Tarzarv and Saiidi (2016) [64] state that the Ni-Ti bond to concrete is greater in the surrounding area of the $\mathrm{Ni}-\mathrm{Ti}$ - steel bar connectors.

Both the separation between cracks and the crack opening are directly influenced by the $\mathrm{Ni}-\mathrm{Ti}$ bond because the tensile force in the bars is not transmitted to the concrete by tangent stresses between cracks (tension stiffening). The specimens should be retested when the state of the art evolves and corrugated $\mathrm{Ni}$-Ti bars are available.

Strain gauges located in $\mathrm{Ni}-\mathrm{Ti}$ bars registered different strains along the same $\mathrm{Ni}$-Ti bar. If there was no bond, all the gauges 


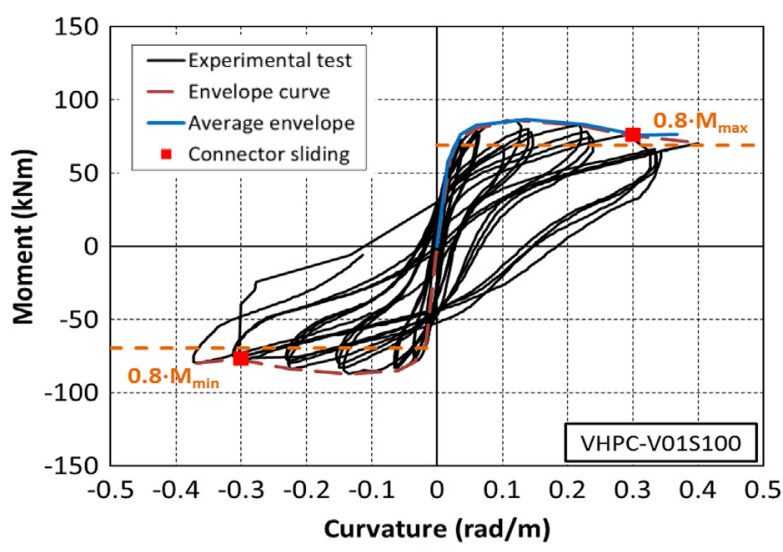

(a)

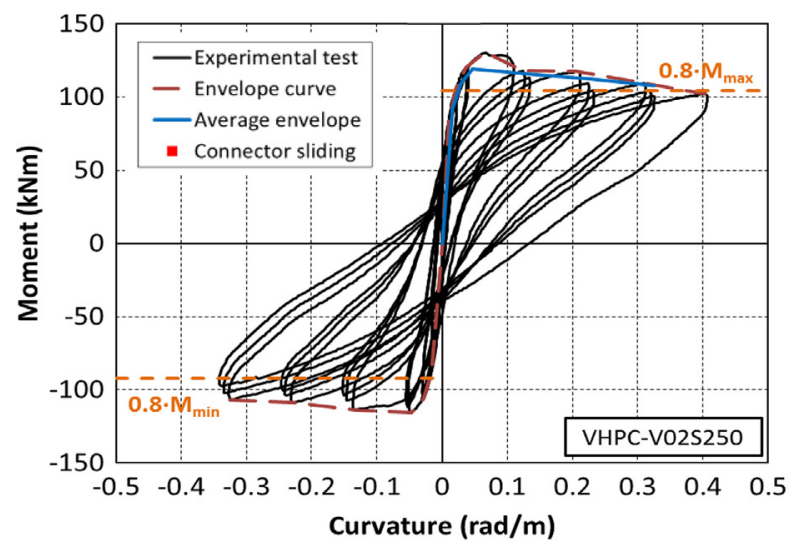

(c)

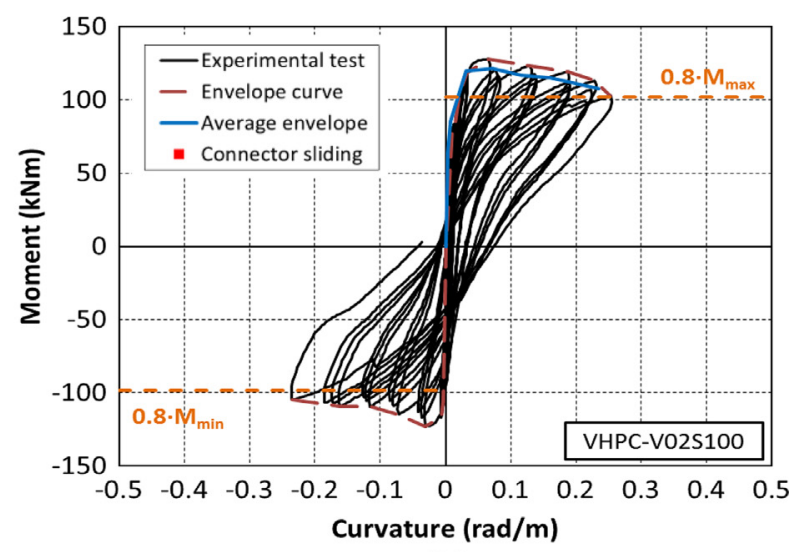

(b) would register the same strain. Unfortunately, the gauges failed shortly after maximum load was reached. For higher strains it is unknown if the bars continued to maintain a certain bond with the concrete. The reason that all gauges failed is that the glue is designed to glue the gauges to the steel and not to the Ni-Ti surface (both surfaces are chemically different). When the cracking became prominently, the gauges lost the bond with the Ni-Ti bars.

\section{Numerical model calibration}

In this section, the calibration and validation of a finite element numerical model done with the OpenSees program [65] were carried out. A nonlinear static cyclic pushover analysis was performed, and calibration was carried out with the specimens tested in the experimental program.

\subsection{Model description}

A finite element model was made to simulate the specimens tested in the experimental campaign described in Section 2. Finite elements were one-dimensional and had two nodes (at the ends). As it was a two-dimensional problem, each node had three active degrees of freedom: two translations on the plane and one rotation perpendicular to the plane. Fig. 19 shows the position of the nodes, the boundary conditions of the model and the applied loads. The extreme nodes (0-180 and 3120-3300) were joined with a RigidLink because it represents the metallic frame (nondeformable) located at the ends of specimens (see Fig. 2). RigidLink imposed kinematic equations of a rigid body between both nodes. Elements
E7 and E8 had the stub section $(860 \times 150 \mathrm{~mm})$ and the rest of the element had the support section $(260 \times 150 \mathrm{~mm})$. Elements E8E10 had Ni-Ti reinforcements, while the rest had steel reinforcements. Elements E4-E7 were reinforced with an additional steel bar on both the upper and lower faces so that failure would occur in the semi-column reinforced with Ni-Ti bars (Fig. 1). This extra reinforcement was also added in the experimental tests. Three analyses were carried out per specimen: (a) in the first, the distributed load due to own weight was applied; (b) in the second, axial force $(\mathrm{N})$ was applied; $(\mathrm{c})$ in the third, cyclic load $\left(F_{v}\right)$ was applied. In the first two analyses, a force control was used until the target load was reached, in the third one, displacement control was employed where the drift ratio protocol of the experimental campaign was applied (Fig. 7). For this purpose, unit load $F_{v}$ was applied, which was multiplied by OpenSees [65] until the target drift ratio was reached in each cycle. The solution algorithm was Newton-Raphson. The convergence criterion was that the 2-norm of the unbalanced forces vector was below $10^{-10}$.

\subsection{Material constitutive models}

For conventional B500SD steel, the existing Steel02 material of OpenSees [65] was used. This material is based on the proposal of Menegotto and Pinto [66], and has been subsequently modified by Filippou et al. [67]. The parameters of Steel02 were those obtained in the characterization tests of the reinforcements (Fig. 3).

For the Ni-Ti bars, OpenSees SelfCentering material [65] was used, based on the model by Christopoulos et al. [68]. This material offers perfect superelasticity. The main parameters are the slopes 


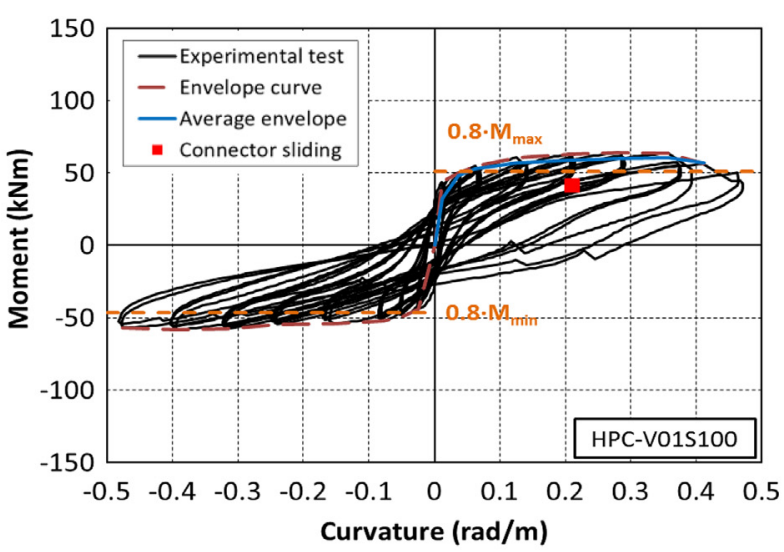

(a)

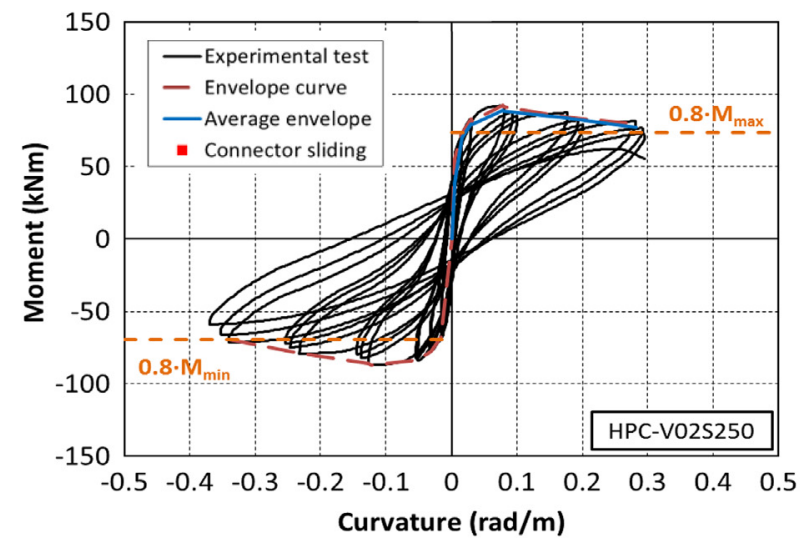

(c)

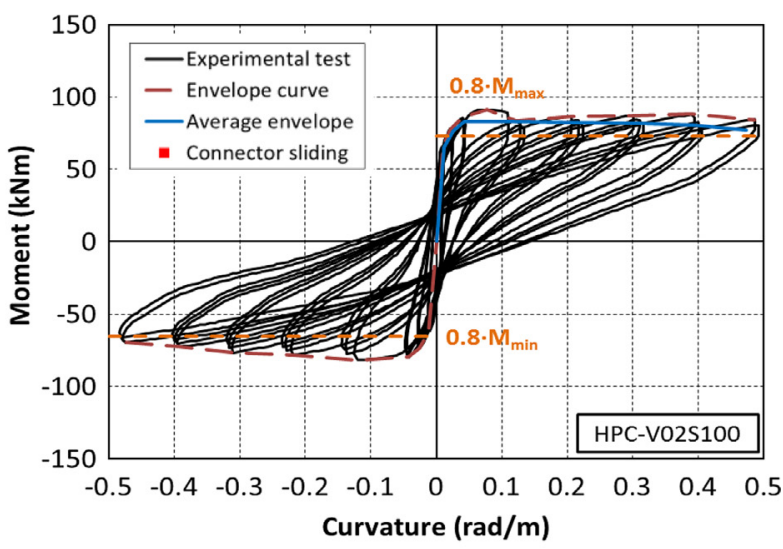

(b)

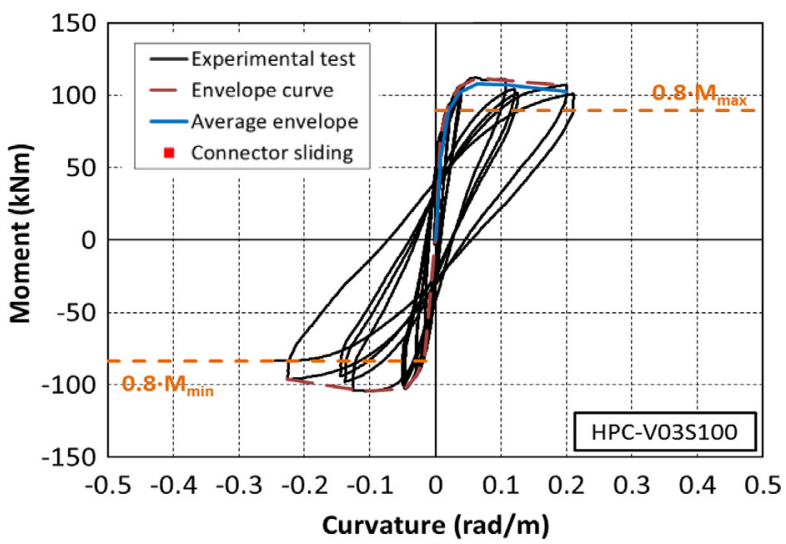

(d)

Fig. 12. Experimental moment-curvature response for the HPC specimens.

Table 4

Summary of the experimental results.

\begin{tabular}{|c|c|c|c|c|c|c|c|c|c|c|c|c|c|c|c|}
\hline Id & Specimen & $\frac{N}{b \cdot h \cdot f_{c m}}$ & $\frac{V_{\max }}{b \cdot h \cdot f_{c m}}$ & $\frac{M_{\max }}{b \cdot h^{2} \cdot f_{c m}}$ & $\begin{array}{l}\Delta_{\mathrm{yl}} \\
(\mathrm{mm})\end{array}$ & $\begin{array}{l}\Delta_{\mathrm{u}} \\
(\mathrm{mm})\end{array}$ & $\mu_{\Delta \mathrm{u}}$ & $\begin{array}{l}\varphi_{\mathrm{yI}}\left(10^{-3} \mathrm{rad} /\right. \\
\mathrm{m})\end{array}$ & $\begin{array}{l}\varphi_{\mathrm{u}}\left(10^{-3} \mathrm{rad} /\right. \\
\mathrm{m})\end{array}$ & $\mu_{\varphi u}$ & $\begin{array}{l}\mathrm{E}_{\text {sum }} \\
(\mathrm{kN} \cdot \mathrm{m})\end{array}$ & $\mathrm{E}_{\mathrm{N}}$ & $\begin{array}{l}\mathrm{K}_{0}(\mathrm{kN} / \\
\mathrm{m})\end{array}$ & $\mathrm{l}_{\mathrm{cr}} / \mathrm{h}$ & $l_{p} / h$ \\
\hline 1 & $\begin{array}{l}\text { VHPC- } \\
\text { V01S100 }\end{array}$ & 0.10 & 0.011 & 0.069 & 6.30 & $53.85^{*}$ & $8.55^{*}$ & 31.57 & $367.61^{*}$ & $11.64^{*}$ & 30.64 & 24.35 & 5848 & 0.46 & 0.38 \\
\hline 2 & $\begin{array}{l}\text { VHPC- } \\
\text { V02S100 }\end{array}$ & 0.20 & 0.015 & 0.101 & 8.10 & 44.70 & 5.52 & 14.19 & 234.80 & 16.55 & 45.95 & 22.40 & 7862 & 0.54 & 0.46 \\
\hline 3 & $\begin{array}{l}\text { VHPC- } \\
\text { V02S250 }\end{array}$ & 0.20 & 0.015 & 0.099 & 9.30 & 45.90 & 4.94 & 21.48 & 324.59 & 15.11 & 35.57 & 19.52 & 7371 & 0.46 & 0.31 \\
\hline 4 & $\begin{array}{l}\text { HPC- } \\
\text { V01S100 }\end{array}$ & 0.10 & 0.012 & 0.080 & 4.95 & $67.95^{*}$ & $13.73^{*}$ & 43.42 & $411.14^{*}$ & $9.47^{*}$ & 27.64 & 27.59 & 4082 & 0.46 & 0.46 \\
\hline 5 & $\begin{array}{l}\text { HPC- } \\
\text { V02S100 }\end{array}$ & 0.20 & 0.016 & 0.101 & 7.95 & 51.90 & 6.53 & 15.86 & 473.50 & 29.85 & 41.28 & 28.85 & 5348 & 0.54 & 0.27 \\
\hline 6 & $\begin{array}{l}\text { HPC- } \\
\text { V02S250 }\end{array}$ & 0.20 & 0.016 & 0.104 & 8.10 & 49.20 & 6.07 & 19.25 & 281.84 & 14.64 & 22.90 & 18.36 & 6027 & 0.85 & 0.42 \\
\hline 7 & $\begin{array}{l}\text { HPC- } \\
\text { V03S100 }\end{array}$ & 0.30 & 0.019 & 0.134 & 9.15 & 48.60 & 5.31 & 22.98 & 200.47 & 8.72 & 12.72 & 10.14 & 6055 & 0.46 & 0.62 \\
\hline
\end{tabular}

"Values obtained considering that envelope passes through one loading cycle in which the bar slid within the connector.

of the austenitic branch and martensitic transformation, stress at the start of the martensitic transformation (both in loading and unloading) and strain at the start of the martensitic branch. All the parameters were extracted from the results of the mechanical characterization of $\mathrm{Ni}-\mathrm{Ti}$ (Fig. 4).

Both VHPC and HPC were modeled with the Engineered Cementitious Composites Material (ECC01) material of OpenSees [65] based on the model by Han et al. [69]. The compression branch of HPC was idealized according to the constitutive equation proposed by Campione et al. [10] for confined high strength concrete with steel fibers. The compression branch of VHPC was idealized according to Setra [70] (Fig. 20a) modified to consider the stirrup confinement according to Cusson and Paultre [71]. The stressstrain relationships in tension (Fig. 20b) were deduced from the results of the flexural tensile tests (UNE EN 14651:2007 [53]). These relationships were formed by four branches determined from an inverse analysis of the flexural tensile tests. Fig. 20c shows the stress - crack width relationship of flexural tensile tests according to UNE EN 14651:2007 [53], were both relationships match one over another. 


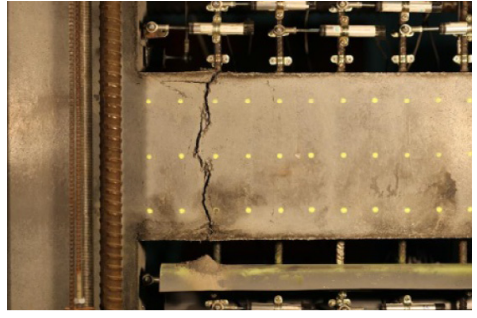

(a) VHPC-V01S100 $\left(\Delta / \mathrm{L}_{\mathrm{s}}=5 \%\right)$

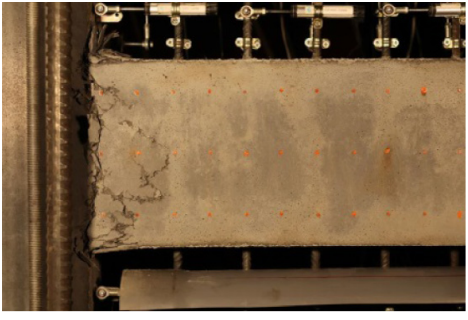

(b) VHPC-V02S100 $\left(\Delta / L_{s}=5 \%\right)$

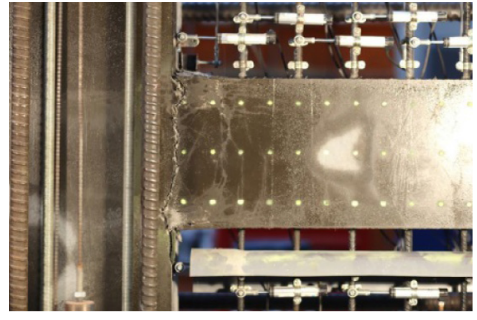

(c) VHPC-V02S250 $\left(\Delta / L_{s}=5 \%\right)$

Fig. 13. Specimen behavior at ultimate state. VHPC specimens.

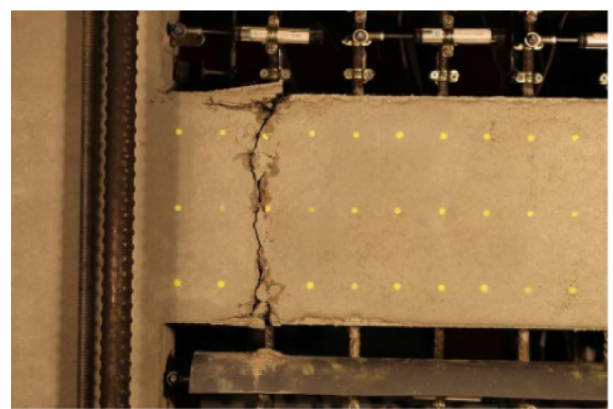

(a) HPC-V01S100 $\left(\Delta / L_{s}=6 \%\right)$

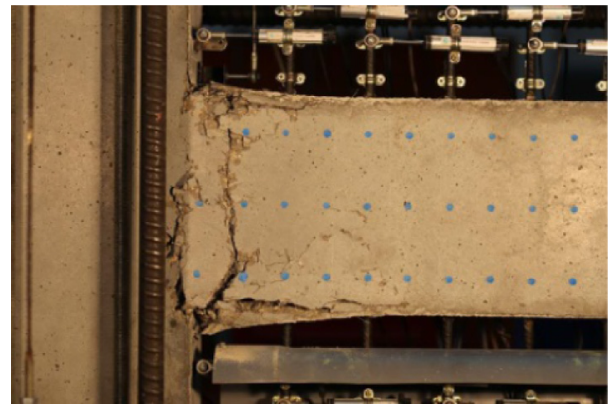

(c) HPC-V02S250 $\left(\Delta / \mathrm{L}_{\mathrm{s}}=4 \%\right)$

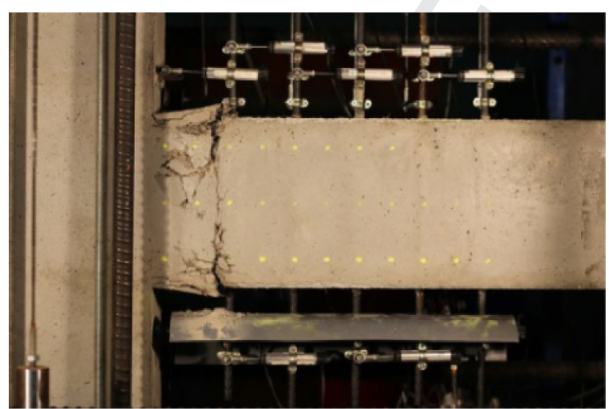

(b) HPC-V02S100 $\left(\Delta / L_{s}=5 \%\right)$

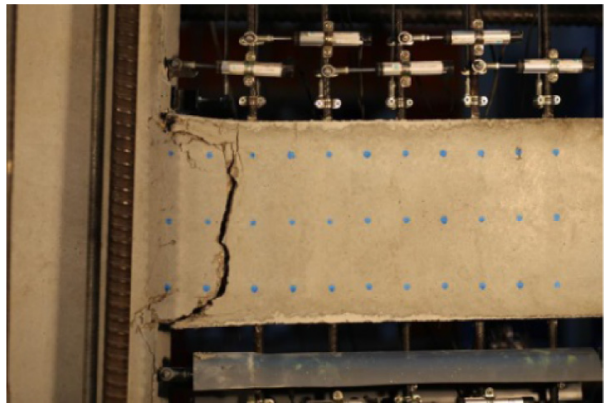

(d) HPC-V03S100 $\left(\Delta / L_{s}=3 \%\right)$

Fig. 14. Specimen behavior at ultimate state. HPC specimens.

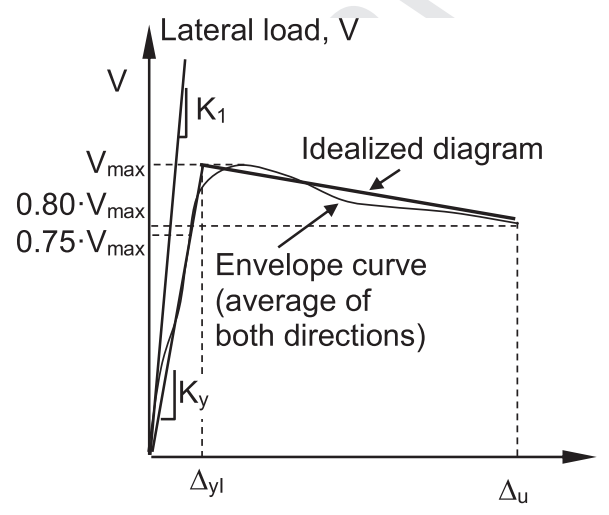

Tip displacement, $\Delta$

(a)

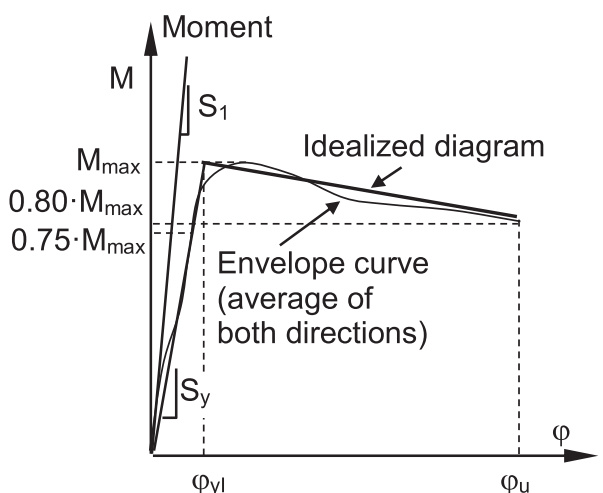

Curvature, $\varphi$

(b)

Fig. 15. Ideal curve definitions. 


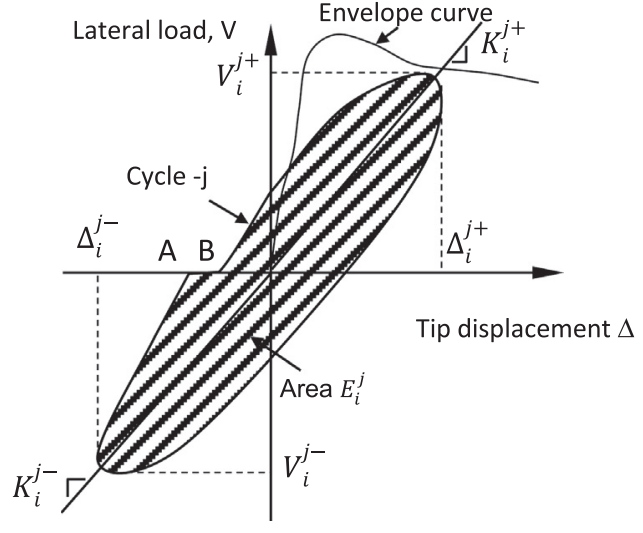

Fig. 16. Energy dissipation.

\subsection{Calibration with the experimental results}

Numerical model calibration was done by adjusting the size of the finite elements and drift increment in each iteration. Next maximum load $V_{\max }$, ultimate load $V_{u}$, which corresponded to ultimate displacement $\Delta_{u}$, the drift ratio for maximum load $\Delta_{\max } / L_{s}$, the ultimate drift ratio $\Delta_{u} / L_{s}$ and displacement ductility $\mu_{\Delta u}$ of the specimens were compared in both the numerical the experimental tests. Displacement ductility $\mu_{\Delta u}$ was obtained according to the criterion described in Section 3.2 (Fig. 15). Fig. 21 and Fig. 22 show the diagrams that compare the load-drift curves of the experimental tests with those provided by the calibrated numerical model. Fig. 23 displays the M-c diagrams for specimens VHPC-V02S100 and HPCV02S100. As we can see, the numerical model properly fitted both the enveloping curves and the descent slope of the unloading branches. However, this level of precision was not reached for the residual drift ratio, especially in the specimens with a lower axial level (VHPC-V01S100 and HPC-V01S100). This was because the numerical model did not take into account the connector sliding and the SMA material model considered in the OpenSees Software did not adequately represent the behavior of the SMA used in the experimental tests, which was not perfectly superelastic (Fig. 4). The residual drift ratio shown by the numerical model was due to the concrete degradation considered in the constitutive equation of HPC and VHPC. Consequently, nor did the numerical model adequately fit energy dissipation.

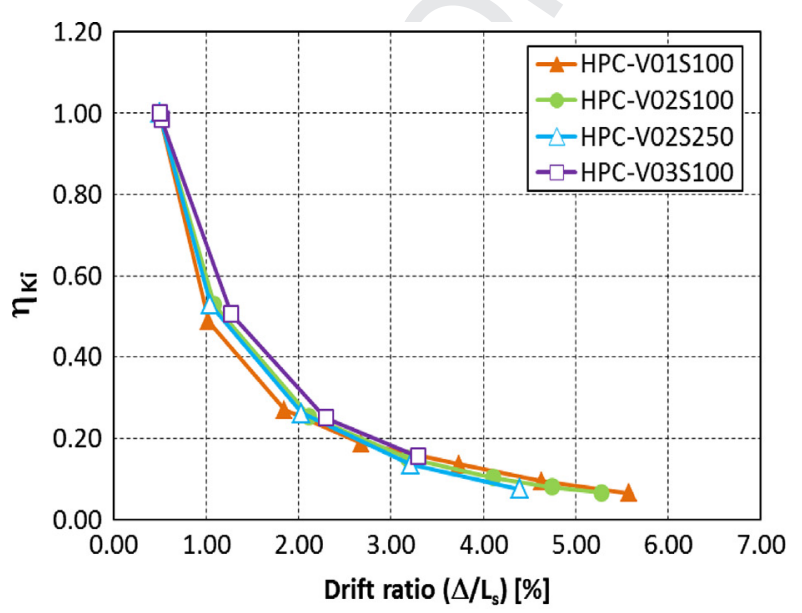

(a)
Table 5 shows the goodness of the numerical model's fit compared with the experimental results, where the degree of precision was obtained as a quotient between the experimental value and that obtained with the numerical model.

In general, ratio $\xi$ of Table 5 is located above the unit so that the numerical model is on the security side. A good approximation can be observed in relation to average displacement ductility (1.07) and a low coefficient of variation (0.05) if the fact that it accumulates the errors that correspond to the calculation of both the effective elastic drift $\left(\Delta_{y I} / L_{s}\right)$ and ultimate drift $\left(\Delta_{u} / L_{s}\right)$ is taken into account. The goodness of fit in relation to maximum load and displacement ductility is shown in Fig. 24.

\section{Parametric study}

A parametric study was conducted in this section considering the numerical model developed and calibrated in OpenSees [65] in Section 0. The influence of several parameters on the strength and deformation capacity was studied in the parametric study. The constitutive equations of the materials calibrated were used (Section 5.2). In this study, the same cross-section of the experimental campaign $(150 \times 260 \mathrm{~mm})$ and the same mechanical concrete cover width of the longitudinal reinforcements $(r / h=0.15)$ were considered.

\subsection{Parameters and numerical tests}

The following parameters were analyzed:

\section{- Relative normal force $(v)$.}

The subsequent values were studied: $0,0.1,0.2,0.3,0.4,0.5$, $0.55,0.6$ and 0.65. According to codes EHE [1]. EC-8 [3] and ACI318 [5], value 0.1 is the minimum relative normal force to consider the specimen to be a support. Value 0.65 is the maximum relative normal force if designing the support with medium ductility (DCM) and value 0.55 if the support is designed with high ductility $(\mathrm{DCH})$.

\section{- Specimen concrete type.}

Two concrete types were analyzed: HPC and VHPC. The average mechanical properties of the experimental campaign were used as a reference (Table 3 ).

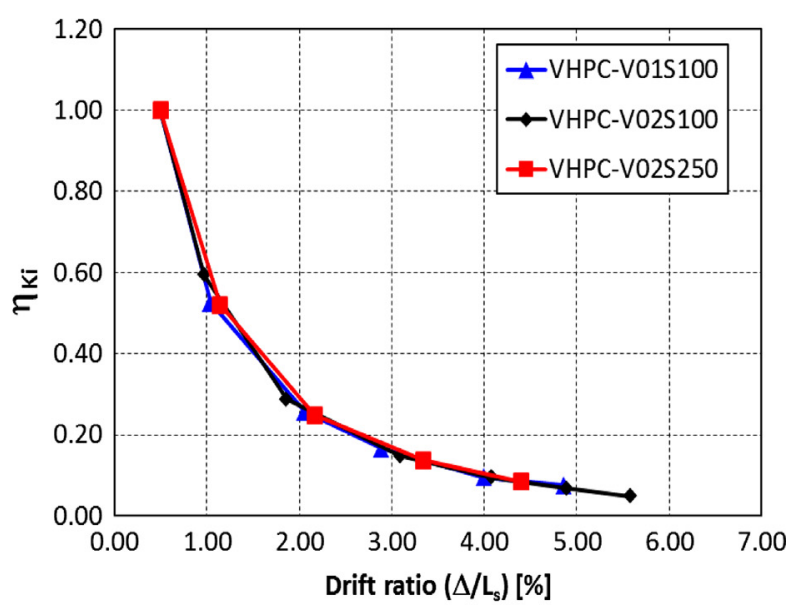

(b)

Fig. 17. Stiffness degradation of specimens. 


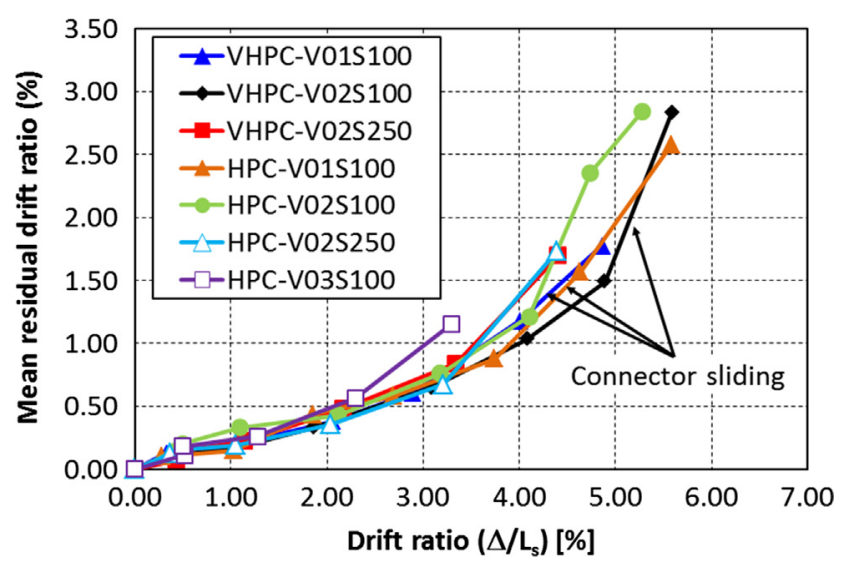

Fig. 18. Residual drift ratio.

\section{- SMA Ni-Ti bars length ( $\left.\mathrm{L}_{S M A}\right)$.}

Five lengths of SMA bars were studied, measured from the center of the stub: $0,300,450,600,750$ and $900 \mathrm{~mm}$. The null length was added to obtain the response of the element when the entire longitudinal reinforcement was formed by steel B500SD.

\section{- Tie spacing $\left(s_{t}\right)$.}

Five transverse reinforcement separations were considered: 50 , $72,100,120$ and $250 \mathrm{~mm}$. The $50 \mathrm{~mm}$ separation was normally the minimum one used. The $72 \mathrm{~mm}$ separation was the maximum separation proposed by the regulations for both high ductility $(\mathrm{DCH})$ in EC-8 [3] and the special structures in ACI-318 [5], which equaled $6 \mathrm{D}$, being $\mathrm{D}$ the diameter of the longitudinal bar that equals 12 $\mathrm{mm}$. The $100 \mathrm{~mm}$ separation equaled the experimental value taken and was approximately 8D, which coincided with the maximum transverse reinforcement separation for both medium ductility (DCM) according to EC-8 [3] and ordinary structures according to ACI-318 [5]. The $120 \mathrm{~mm}$ value was 10D and represented an intermediate value, while $250 \mathrm{~mm}$ coincided with the experimentally analyzed second tie spacing value, which was approximately 20D as EC-2 [72] suggests, this being the maximum value of current design codes.

\section{- Shear slenderness $\left(\lambda_{\mathrm{v}}\right)$.}

Five shear slenderness levels were considered: 3, 4, 5.77, 8 and 10. The shear slenderness of the specimens of the experimental campaign was 5.77. Slenderness $\lambda_{v}$ was calculated as the quotient between equivalent cantilever support length $L_{s}$ and cross-section depth $h$. EC-8 [3] can be applied to columns with shear slenderness below 10 .

\section{- Longitudinal reinforcement ratio $\left(\rho_{1}\right)$.}

Five longitudinal reinforcement ratio levels were studied: $0.5 \%$, $1.16 \%, 1.5 \%, 2.0 \%$ and $2.5 \%$. The expression of the adopted longitudinal reinforcement ratio was: $\rho_{l}=A_{s} / A_{g}$, where $A_{s}$ is the total steel area in the cross-section and $A_{g}$ is the area of gross crosssection. The ratio considered in the experimental campaign was $1.16 \%$.

The parametric study was arranged in five studies (Table 6). In the first study, the effect of both relative normal force and concrete type was analyzed. In the other studies the influence of a particular parameter was analyzed, but relative normal force and concrete type continued to also vary.

\subsection{The parametric study results.}

A nonlinear static monotonic pushover analysis was carried out to obtain the envelope. Both maximum lateral load $\left(V_{\max }\right)$ and displacement ductility $\mu_{\Delta u}$, which was obtained according to the criterion described in Section 3.2 (Fig. 15), were analyzed.

\subsubsection{Relative normal force and concrete type}

Fig. 25 shows the results obtained with the numerical model. As expected, the specimens manufactured with VHPC showed greater strength capacity $\left(V_{\max }\right)$. Regarding displacement ductility $\left(\mu_{\Delta u}\right)$, the specimens manufactured with HPC were more ductile. According to Fig. 25b, the greatest differences in displacement ductility between HPC and VHPC specimens takes place for a range of relative normal forces between 0 and 0.2 . Beyond relative normal force of 0.2 , differences of ductilities of both types of specimens are lower.

\subsubsection{Length of SMA Ni-Ti bars}

Fig. 26 shows the results of the parametric study regarding the length of SMA NI-Ti bars for VHPC columns. The maximum lateral load $\left(V_{\max }\right)$ decreased as the length of Ni-Ti bars increased. This reduction in maximum load was due to the stress at the start of martensitic transformation $\left(f_{A}=450.2 \mathrm{MPa}\right)$ was lower than the yield stress of steel $\left(f_{y}=562.58 \mathrm{MPa}\right)$, and also because the lower stiffness of the Ni-Ti bars caused a greater second-order moment generated by axial load. This reduction was practically linear with the SMA Ni-Ti bar length and was similar for the different analyzed relative normal force levels. Displacement ductility $\left(\mu_{\Delta u}\right)$ increased as the length of the Ni-Ti bars increased. If we compare the behavior of an element with no Ni-Ti bars $\left(\mathrm{L}_{S M A}=0\right)$ to an element with SMA Ni-Ti bars whose length was $900 \mathrm{~mm}$, both an average reduction in lateral load $\left(V_{\max }\right)$ of $21 \%(C . V .=6.02 \%)$ and an increased displacement ductility $\left(\mu_{\Delta u}\right)$ of $299 \%$ (C.V. $=6.05 \%$ ) were observed. The cause of the increase in ductility is that slope of the transformation branch of the constitutive curve of $\mathrm{Ni}-\mathrm{Ti}$ is not null, in contrast to steel yield plateau. For this reason, Ni-Ti is able to partially counter the load capacity loss caused by concrete degradation. As a consequence, the ultimate displacement of the column that corresponds to $80 \%$ of the maximum load on the post-peak branch $\left(\Delta_{u}\right)$ is higher in Ni-Ti reinforced specimens than in the steel reinforced specimens and, consequently, the ductility $\mu_{\Delta u}=\Delta_{u} / \Delta_{y I}$ is higher too. The increase in ductility was greater than strength capacity loss.

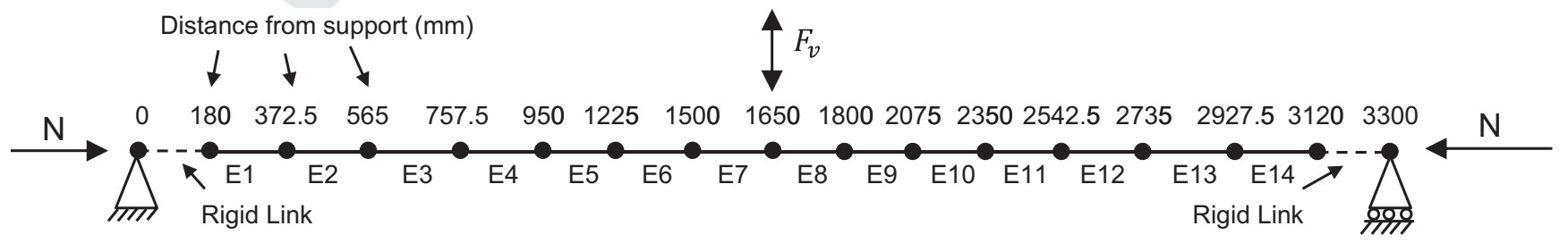

Fig. 19. Finite element model configuration (unit: $\mathrm{mm}$ ). 


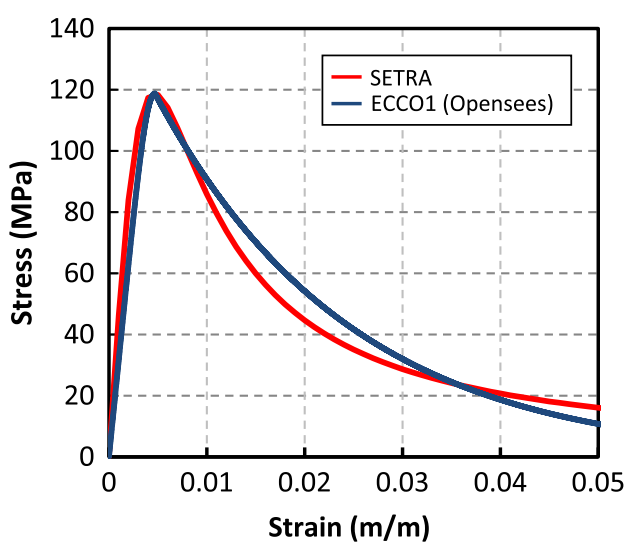

(a)

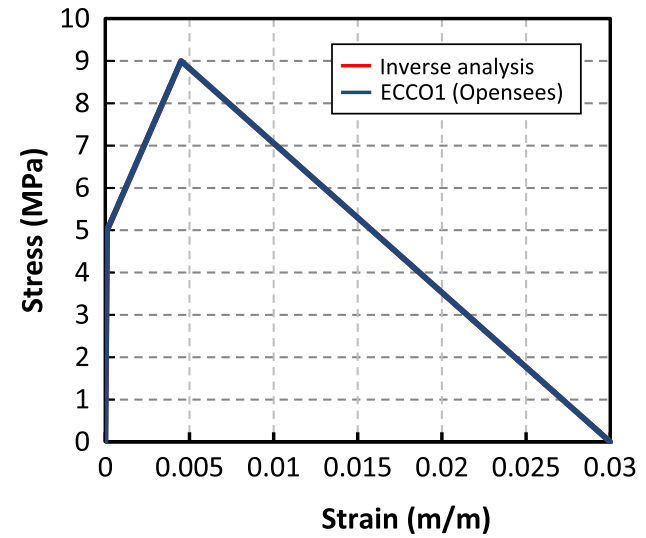

(b)

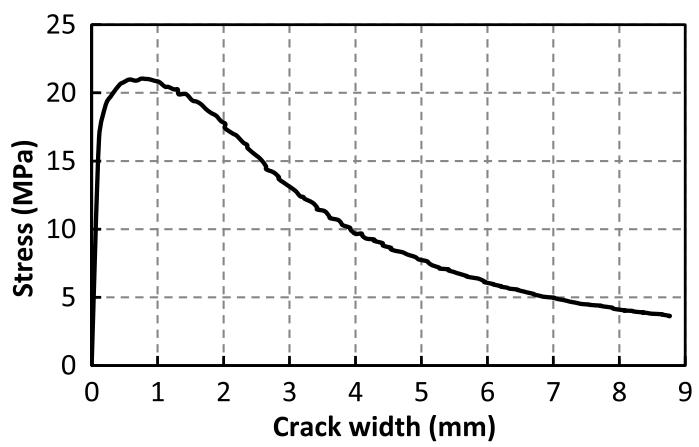

(c)

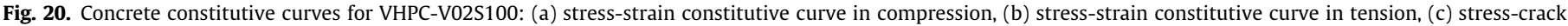
width constitutive curve.

\subsubsection{Tie spacing}

Fig. 27 shows the results of the parametric study regarding tie spacing for VHPC columns. The greater the transverse reinforcement separation, the lower the maximum lateral load $\left(V_{\max }\right)$ became. This decrease occurred similarly for all the relative normal force levels. The greatest capacity increase occurred in the interval between 50 and $72 \mathrm{~mm}$. Transverse reinforcement separation caused an $18 \%$ drop in the maximum lateral load in the worst analyzed case. This case corresponded to a VHPC element with a relative normal force of 0.4 in which the separation of the stirrups from 50 to $180 \mathrm{~mm}$ varied.

Displacement ductility $\left(\mu_{\Delta u}\right)$ decreased linearly the more tie spacing increased. The low slope of the curves in Fig. 27b indicated that transverse reinforcement separation did not significantly influence the specimen's deformation capacity. Between the extreme values of the series $\left(s_{t}=50 \mathrm{~mm} v \mathrm{~s} . s_{t}=250 \mathrm{~mm}\right)$, a $15 \%$ $V_{\max }$ reduction (C.V. $=13.11 \%$ ) and a $4 \%$ displacement ductility reduction (C.V. $=16.96 \%$ ) took place because of the decrease of the confinement.

\subsubsection{Shear slenderness}

Fig. 28 shows the results of the parametric study regarding shear slenderness for VHPC columns. The maximum lateral load $\left(V_{\max }\right)$ decreased with shear slenderness because of second-order effects. It should be noted that the influence of the relative normal force on the maximum load for low shear slendernesses $\left(\lambda_{V}=3\right.$ or $\left.\lambda_{V}=4\right)$ was stronger than for high shear slendernesses $\left(\lambda_{V}=10\right)$. Displacement ductility $\left(\mu_{\Delta u}\right)$ also decreased with shear slenderness, but to a lesser extent than the maximum load. This reduction was more pronounced for small relative normal forces. An average
83\% lateral load reduction (C.V. $=4.47 \%$ ) and a $34 \%$ displacement ductility reduction $(C . V .=4.33 \%)$ took place between the extreme values of the series $\left(\lambda_{V}=3 v s . \lambda_{V}=10\right)$.

\subsubsection{Longitudinal reinforcement ratio}

Fig. 29 shows the results obtained with the numerical model for VHPC columns. As expected, the larger the amount of longitudinal reinforcement, the higher the maximum load $\left(V_{\max }\right)$ and the greater displacement ductility $\left(\mu_{\Delta u}\right)$ became. These trends were similar for the different relative normal force levels. Both the average $45 \%$ lateral load (C.V. $=5.59 \%$ ) and the $102 \%$ displacement ductility (C.V. $=6.01 \%)$ increased between the extreme values of the series $\left(\rho_{l}=0.5-2.5 \%\right)$.

\section{Practicalities of the application}

After preforming the experimental tests, the numerical calibration and the parametric study, the following practical rules for designing this type of connection are indicated.

The best combination if lifecycle of structure wants to be increased is VHPC and Ni-Ti bars because of its low damage in comparison to the HPC. If the connectors join Ni-Ti and steel bars with the same diameter (which is the case of this research), the bending moment that a section with steel bars resists is little high than the one that a section with $\mathrm{Ni}$-Ti bars resists according to several bending moment - curvature diagrams were computed for VHPC specimens. They were obtained performing a fiberdiscretization of the section with the material non-linear characteristics used in this research for a relative normal force of $0,0.1$, 0.2 and 0.3 . The results are displayed in Table 7 . In addition, the 


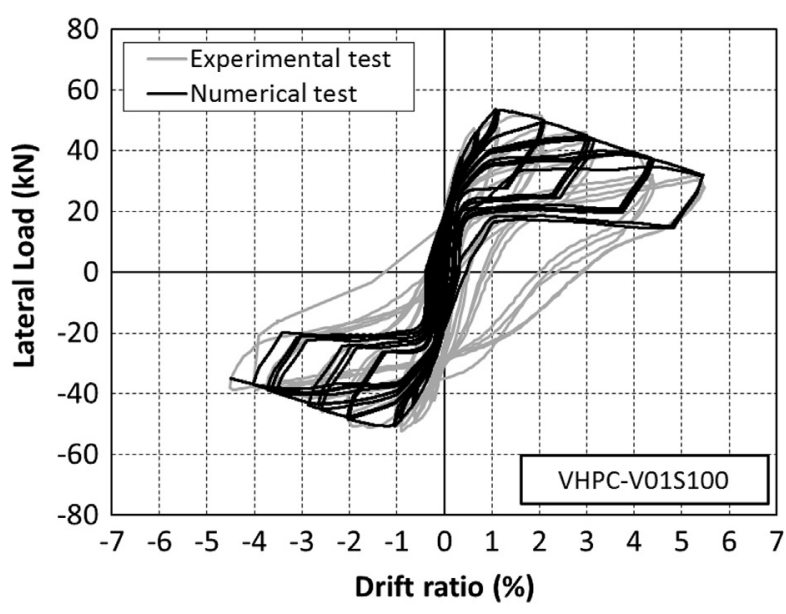

(a)

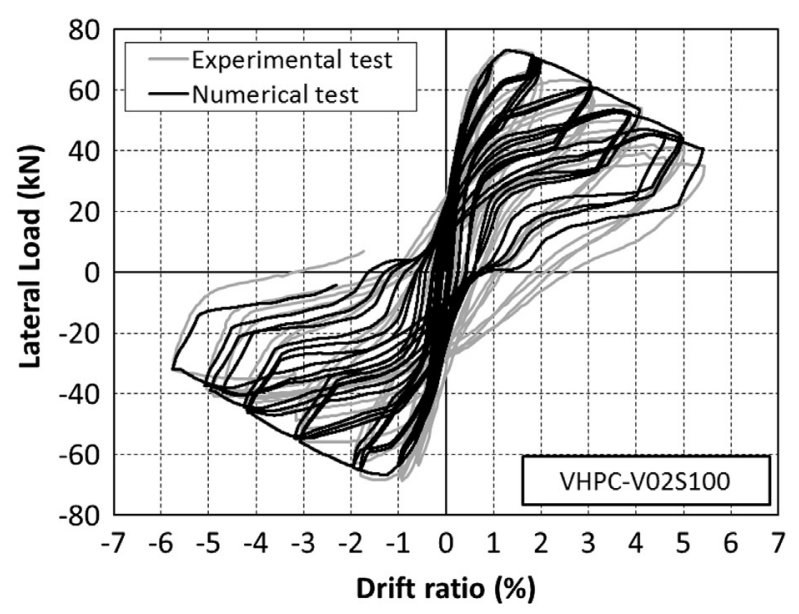

(b)

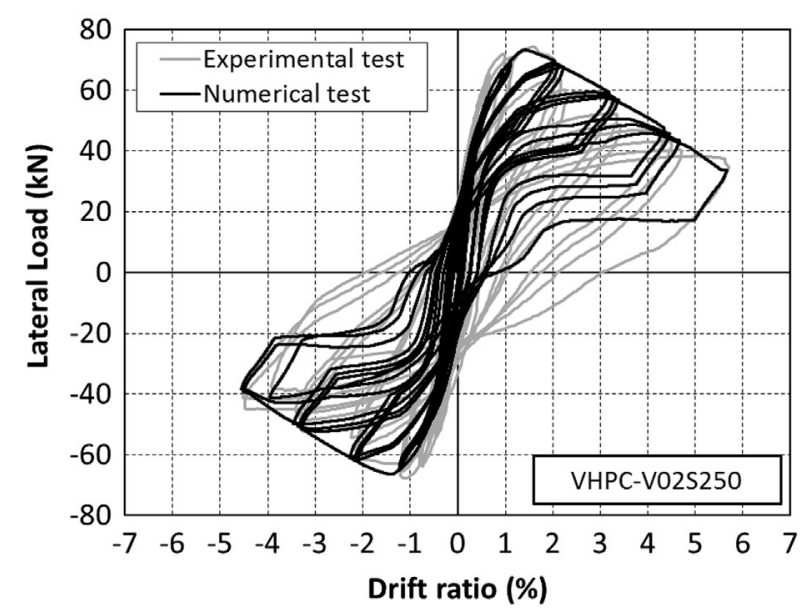

(c)

Fig. 21. Numerical calibration for the VHPC specimens (V-Drift).

section of the column that undergoes the maximum bending moment is made completely of $\mathrm{Ni}$-Ti (stub-column connection). Therefore, when the same diameter of steel and $\mathrm{Ni}$-Ti bars is used, no steel extra-reinforcement is needed. The length of Ni-Ti bars must be enough to contain the plastic hinge.

It must be taken into account that the $\mathrm{Ni}$-Ti used in this research had an onset of martensitic transformation branch above the usual for Ni-Ti (400 vs. $450.2 \mathrm{MPa}$ ). The simulation for a sections with SMA reinforcements with a stress at start of martensitic transformation branch of $400 \mathrm{MPa}$ compared to steel reinforced section generate the results of Table 7 .

If SMA bar diameter is greater than steel bar diameter (unlikely case), a numerical simulation must be carried out to check the strains that concrete reach in both the column - stub connection section and in the section where steel and $\mathrm{Ni}$-Ti bars connect each other through the connector.

\section{Summary and conclusions}

The behavior of both HPC and VHPC supports with SMA (Ni-Ti) reinforcements in the critical region subjected to constant compression and cyclic lateral loading was experimentally studied. Based on these experiments, a numerical model was calibrated to perform a parametric study.

From the experimental study the conclusions are:
1. In the service situation, distributed cracking occurred that could not be perceived by the naked eye, which provided adequate esthetic and durability conditions. In the ultimate state, a single major crack opened in the critical region of the support around which damage took place. This main crack was not generally found in the union section between the support and the stub, but was displaced due to the stub effect, although this section was not subjected under the maximum bending moment. The damage in the specimens manufactured with HPC was greater.

2. A similar critical region length $\left(l_{c r} / h\right)$ was obtained in all cases, which was between 0.46 and 0.54 , except in specimen HSCV02S250 where it was 0.85 .

3. Strength capacity ( $V_{\max }$ and $M_{\max }$ ) was greater in absolute terms in the specimens manufactured with VHPC (42.7\% for $V_{\max }$ and $40.9 \%$ for $M_{\max }$ ) and greater in adimensional terms in those manufactured with HPC (5.5\% for $V_{\max }$ and $7.0 \%$ for $M_{\max }$ ).

4. Displacement ductility $\left(\mu_{\Delta u}\right)$ was $34.0 \%$ higher in the HPC specimens than in VHPC specimens, and lowered with relative normal force $(v)$ (43.9\% from $v=0.1$ to $v=0.2)$, and also with transverse reinforcement separation $\left(s_{t}\right)\left(8.8 \%\right.$ from $s_{t}=100$ $\mathrm{mm}$ to $s_{t}=250 \mathrm{~mm}$ ).

5. A clear tendency for curvature ductility $\left(\mu_{\varphi u}\right)$ was not achieved because $20 \%$ maximum bending moment loss was not accomplished in all the specimens. 


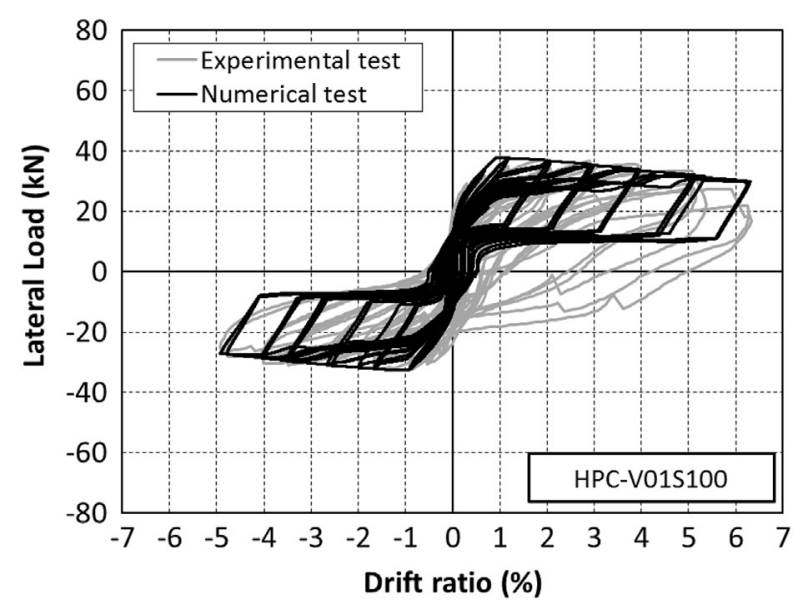

(a)

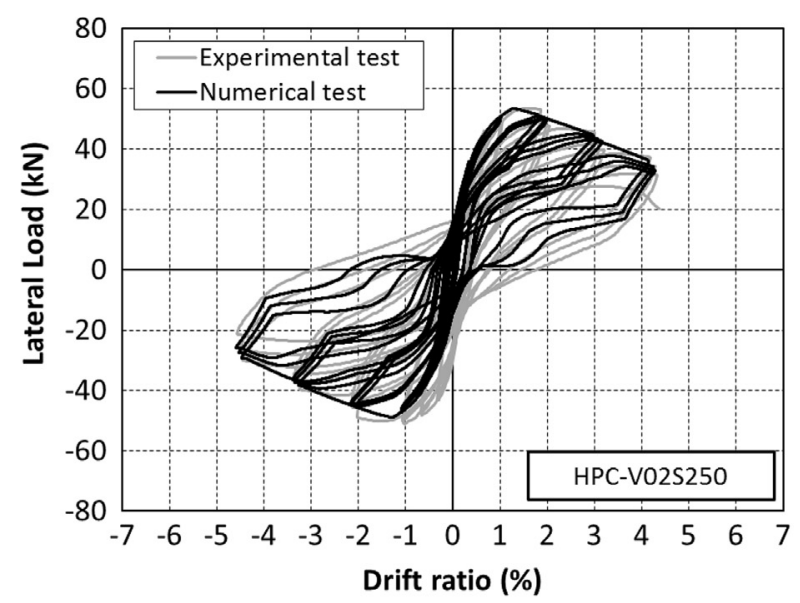

(c)

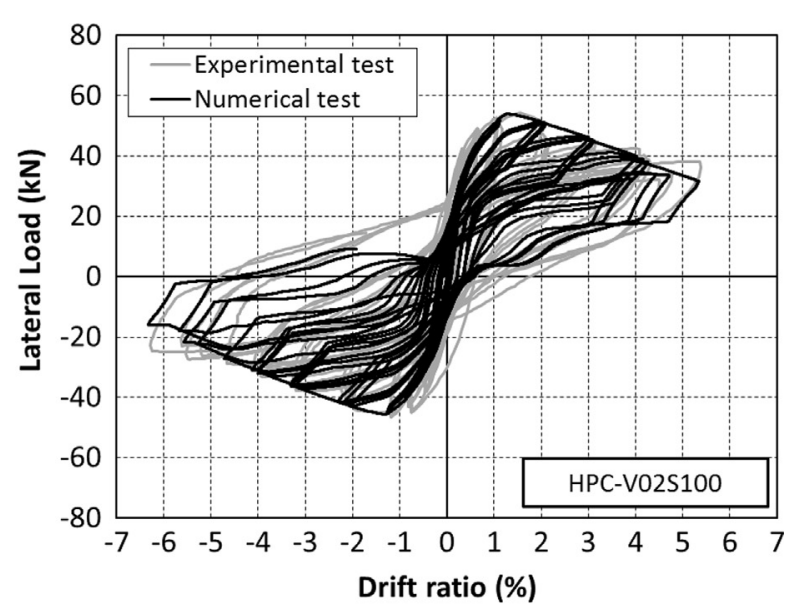

(b)

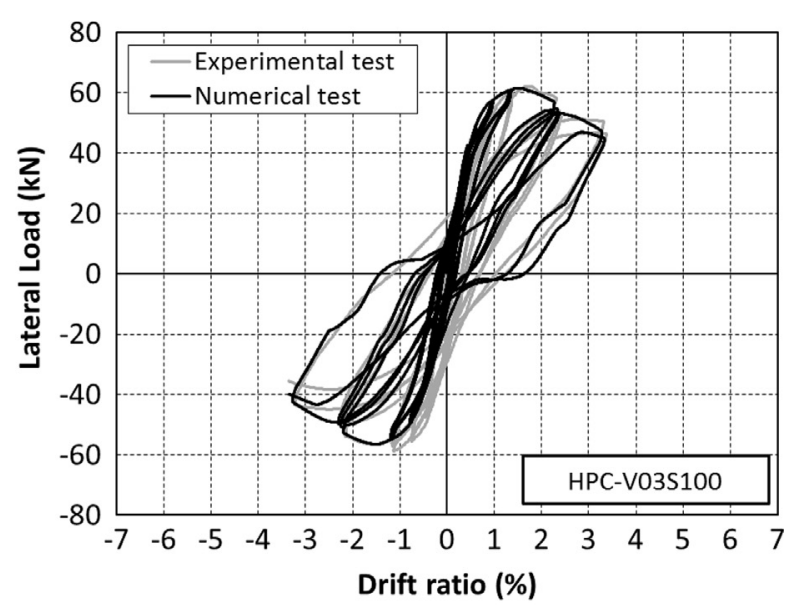

(d)

Fig. 22. Numerical calibration for the HPC specimens (V-Drift).
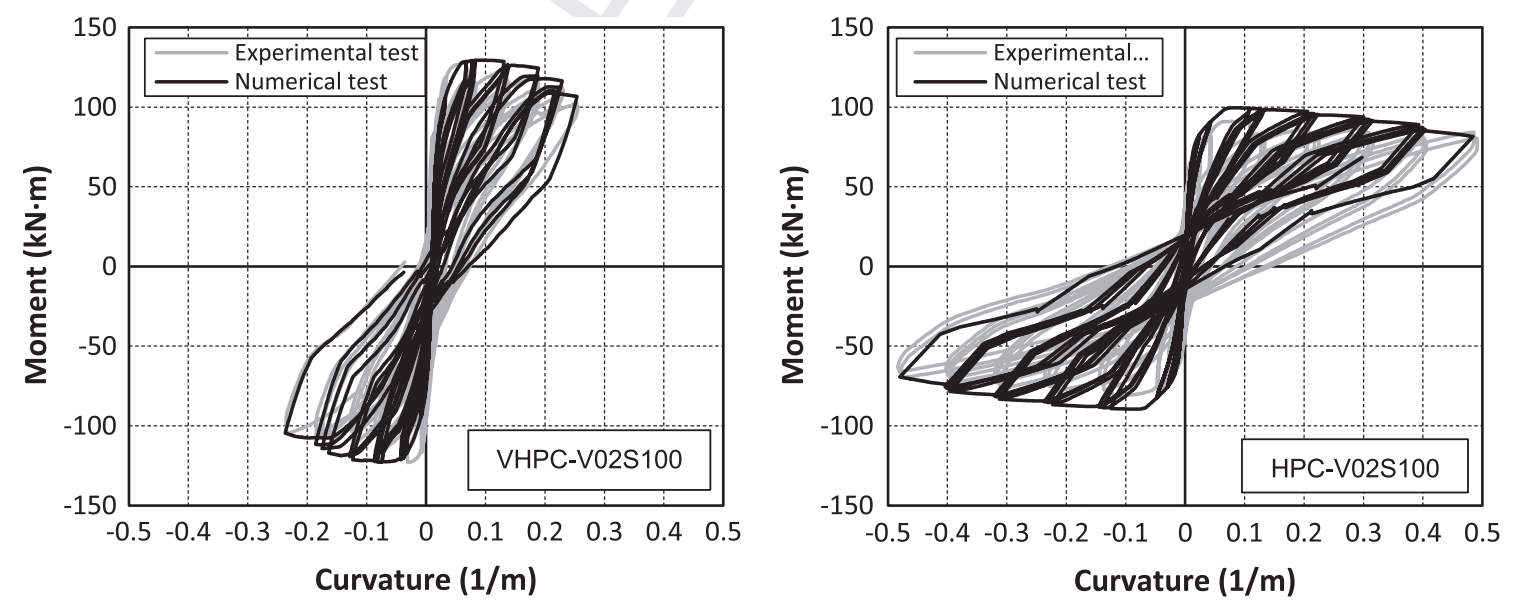

Fig. 23. Numerical calibration M-c diagrams.

6. Normalized dissipated energy $\left(E_{N}\right)$ was $12.1 \%$ greater in the specimens manufactured with HPC in comparison to the VHPC specimens, and reduced with relative normal force $(v)$ and with transverse reinforcement separation $\left(s_{t}\right)$.
7. In general, no significant differences were observed in the stiffness degradation $\left(\eta_{K_{i}}\right)$ between the specimens with either different transverse reinforcement spacing or a different concrete type. Stiffness degradation $\left(\eta_{K_{i}}\right)$ increased with relative normal force $(v)$. 
Table 5

The experimental and numerical results ratio.

\begin{tabular}{|c|c|c|c|c|c|}
\hline \multirow[t]{2}{*}{ Specimen } & \multicolumn{5}{|c|}{ Ratio $\xi$ (experimental/model) } \\
\hline & $V_{\max }$ & $V_{u}$ & $\frac{\Delta_{\max }}{L_{s}}$ & $\frac{\Delta_{u}}{L_{s}}$ & $\mu_{\Delta u}$ \\
\hline VHPC-V01S100 & 0.98 & 1.05 & 1.27 & 1.13 & 1.13 \\
\hline VHPC-V02S100 & 1.01 & 1.05 & 1.21 & 0.96 & 0.98 \\
\hline VHPCV02S250 & 1 & 1.03 & 0.8 & 1.06 & 1.06 \\
\hline HPC-V01S100 & 0.97 & 1.14 & 1.32 & 1.01 & 1.04 \\
\hline HPC-V02S100 & 0.99 & 1.02 & 0.77 & 1.06 & 1.1 \\
\hline HPC-V02S250 & 1.01 & 1.08 & 1.19 & 1.06 & 1.06 \\
\hline HPC-V03S100 & 0.99 & 1.06 & 0.75 & 1.18 & 1.12 \\
\hline Average & 0.99 & 1.06 & 1.04 & 1.07 & 1.07 \\
\hline C.V. & 0.01 & 0.04 & 0.25 & 0.07 & 0.05 \\
\hline
\end{tabular}

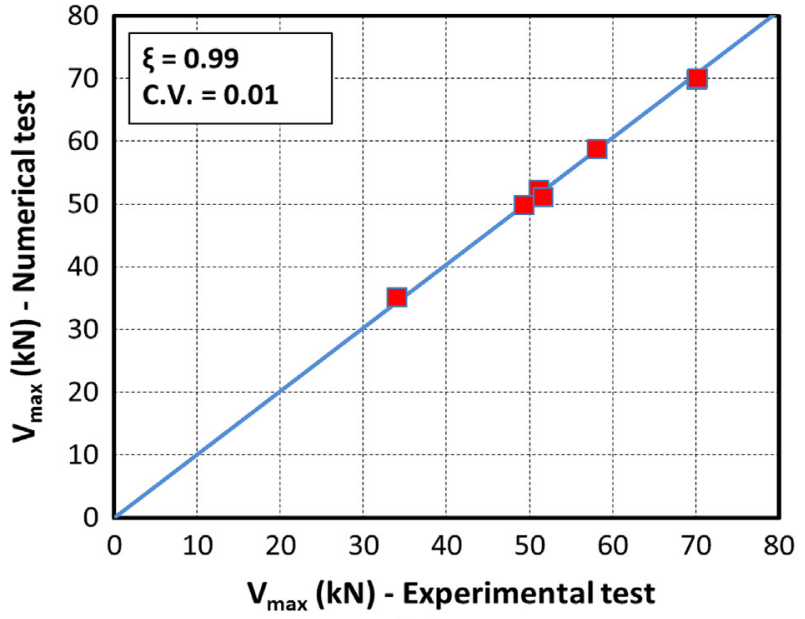

(a)

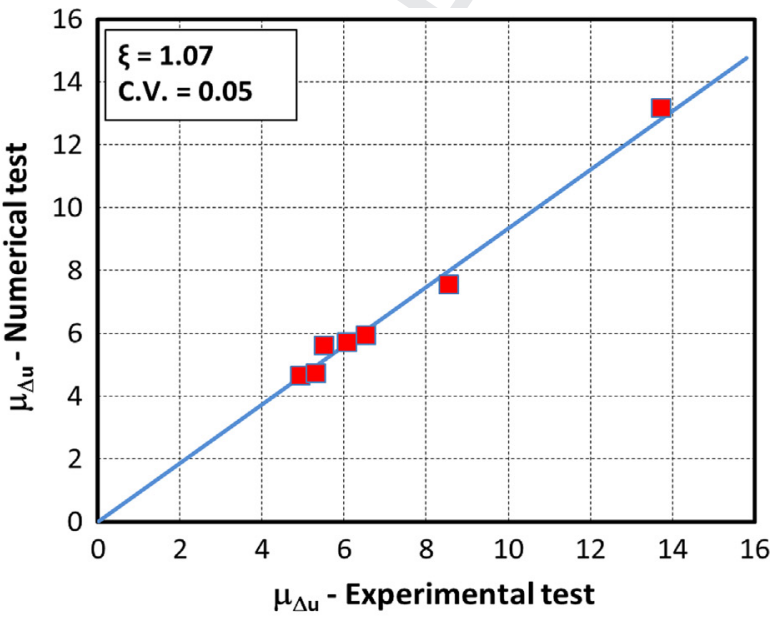

(b)

Fig. 24. Comparison of the results between the numerical and experimental tests.

Table 6

Numerical test program.

\begin{tabular}{|c|c|c|c|c|c|c|c|}
\hline Study & $v$ & Concrete type & $\mathrm{L}_{\mathrm{SMA}}(\mathrm{mm})$ & $s_{t}(\mathrm{~mm})$ & $\lambda_{v}$ & $\rho_{l}(\%)$ & Number of numerical tests \\
\hline Relative normal force and concrete type & $0-0.65$ & HPC, VHPC & 750 & 100 & 5.77 & 1.16 & 18 \\
\hline Length of SMA Ni-Ti bars & $0-0.65$ & HPC, VHPC & 0-900 & 100 & 5.77 & 1.16 & 108 \\
\hline Tie spacing & $0-0.65$ & HPC, VHPC & 750 & $50-250$ & 5.77 & 1.16 & 90 \\
\hline Shear slenderness & $0-0.65$ & HPC, VHPC & 750 & 100 & 3-10 & 1.16 & 90 \\
\hline Longitudinal reinforcement ratio & $0-0.65$ & HPC, VHPC & 750 & 100 & 5.77 & $0.5-2.5$ & 90 \\
\hline
\end{tabular}

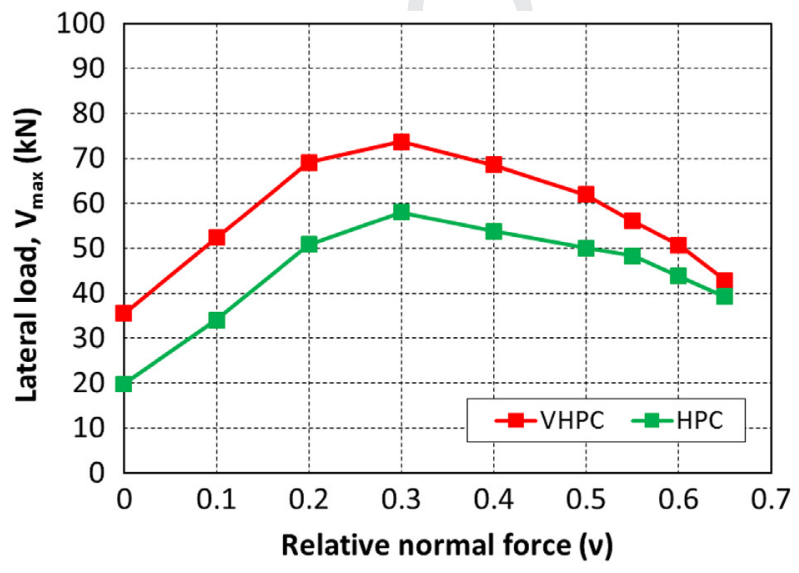

(a)

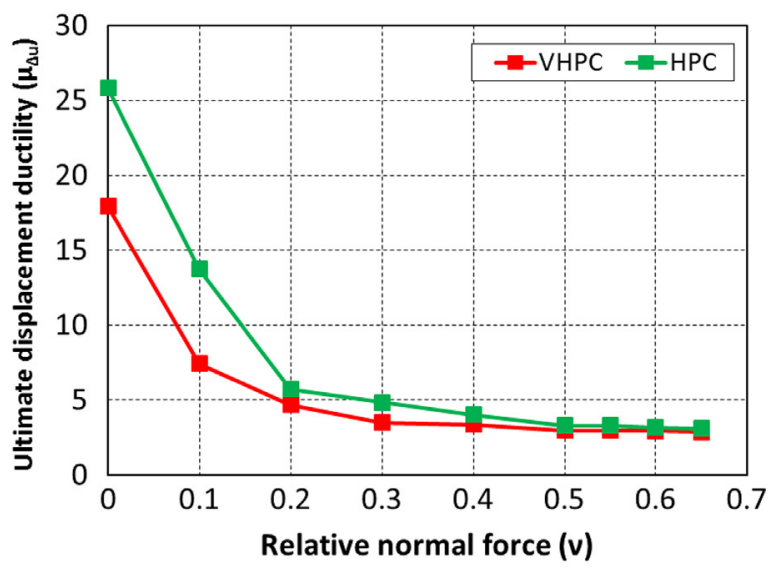

(b)

Fig. 25. Parametric study: relative normal force and concrete type. 


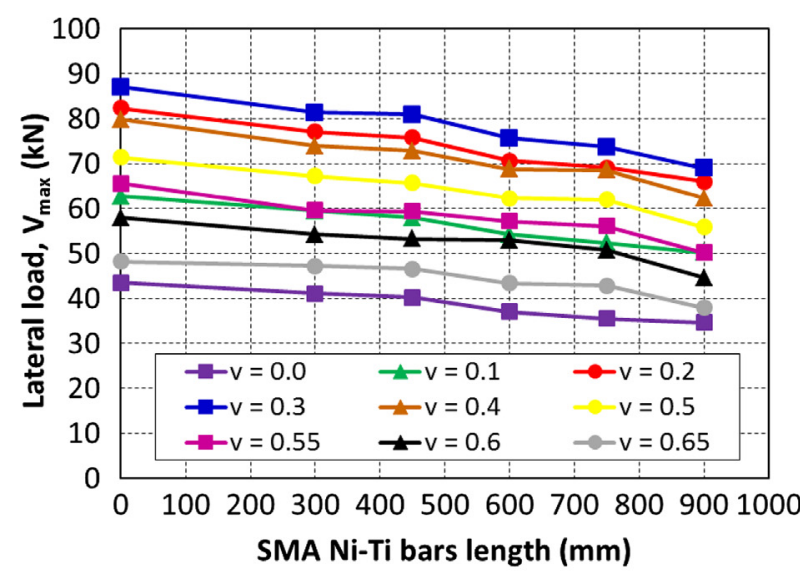

(a)

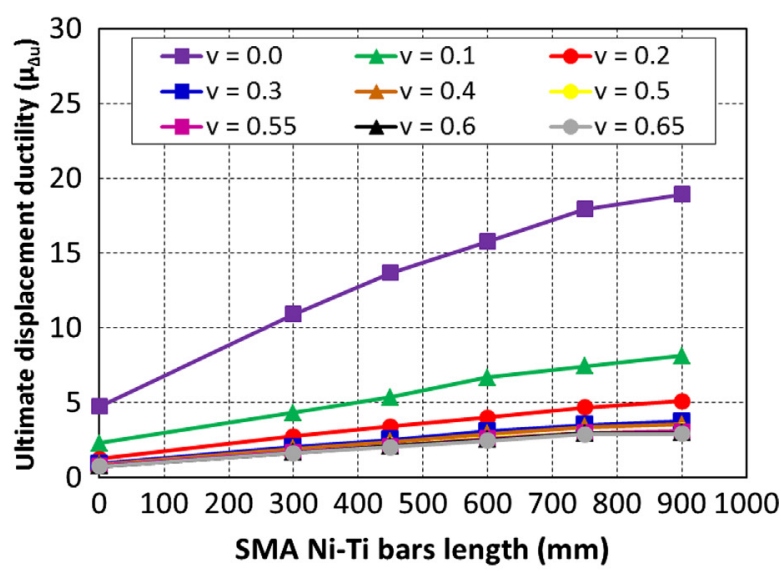

(b)

Fig. 26. Parametric study: length of SMA Ni-Ti bars.

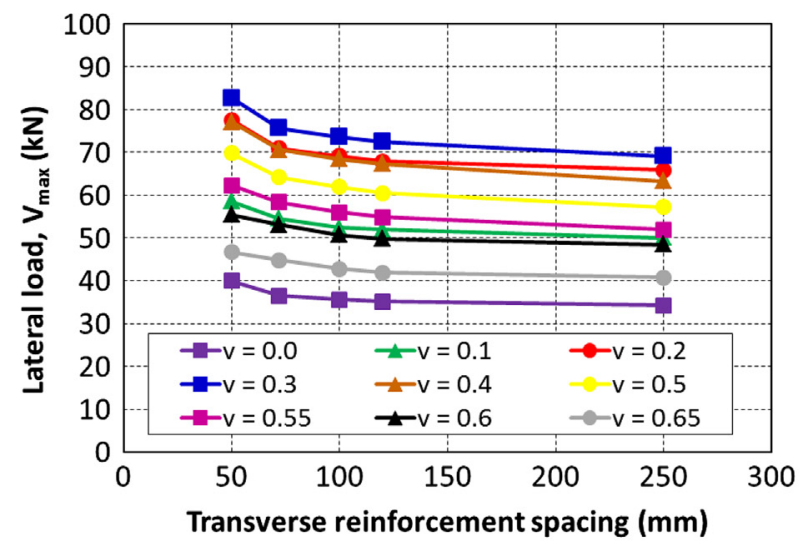

(a)

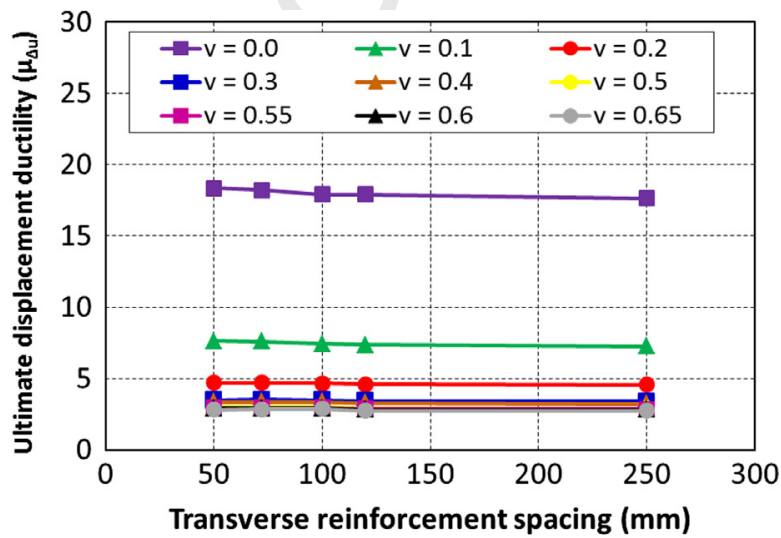

(b)

Fig. 27. Parametric study: tie spacing.

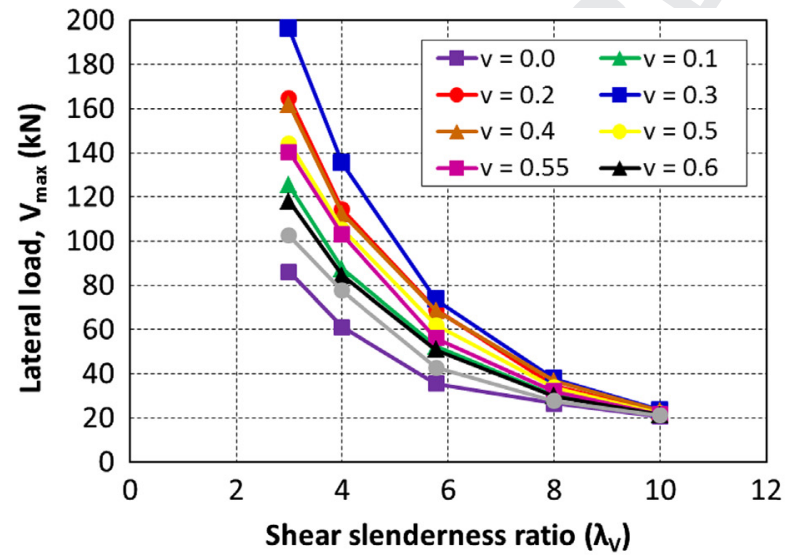

(a)

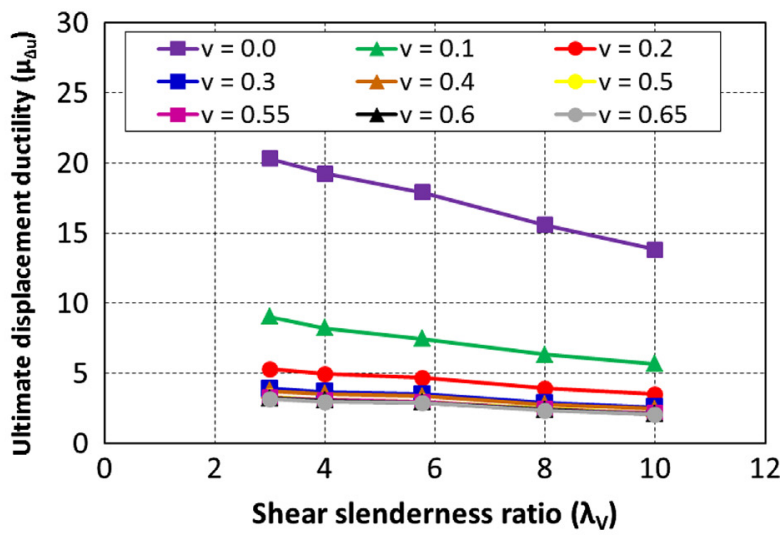

(b)

Fig. 28. Parametric study: shear slenderness.

8. A residual drift ratio below $0.70 \%$ was generally observed for maximum lateral load $V_{\max }$ loss beyond $20 \%$. As a result of progressive concrete cover degradation, especially in the specimens manufactured with HPC, the residual drift ratio increased. This degradation in the HPC specimens occurred due to both the lower steel fibers content and the lesser concrete-fiber adhesion since compressive strength was lower. 


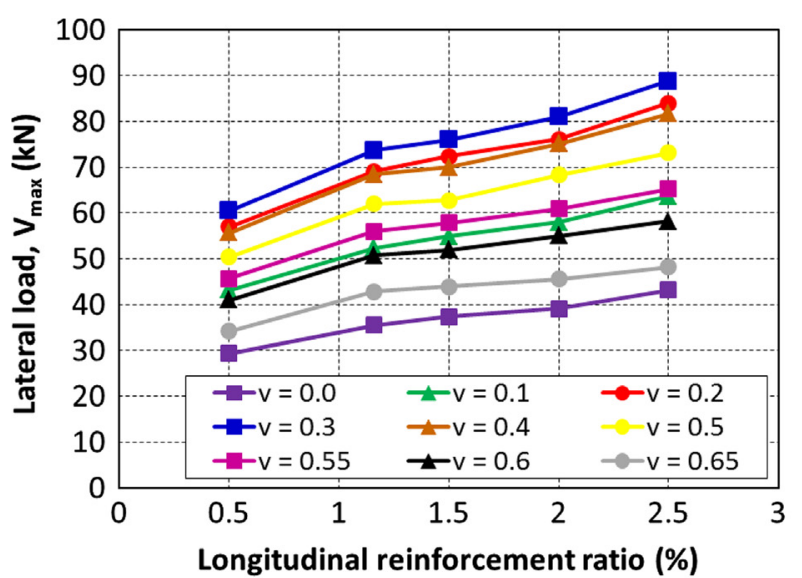

(a)

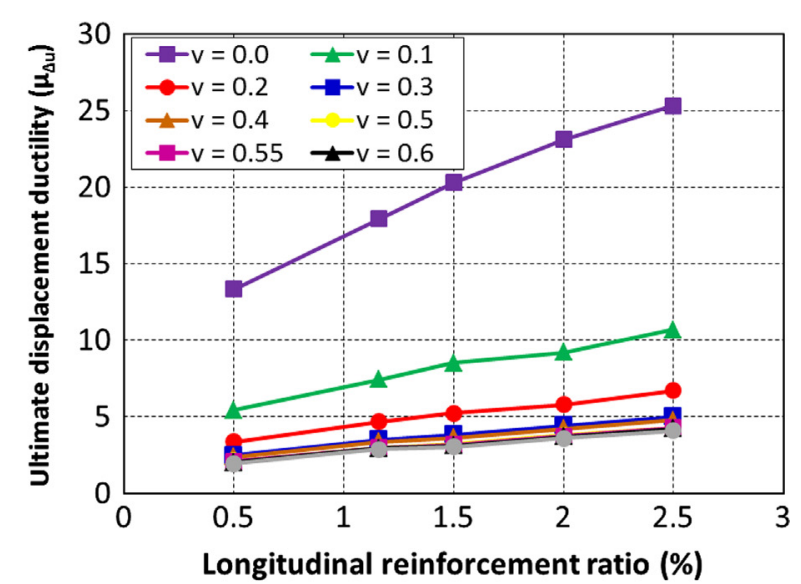

(b)

Fig. 29. Parametric study: longitudinal reinforcement ratio.

Table 7

Comparison of bending moments resisted by a steel and SMA reinforced section.

\begin{tabular}{|c|c|c|c|c|}
\hline $\begin{array}{l}\text { Stress at start of martensitic transformation } \\
\text { branch of } \mathrm{Ni}-\mathrm{Ti}(\mathrm{MPa})\end{array}$ & $\begin{array}{l}\text { Relative } \\
\text { normal force }\end{array}$ & $\begin{array}{l}\text { Bending moment resisted by steel } \\
\text { reinforced sections }(\mathrm{kN} \cdot \mathrm{m})\end{array}$ & $\begin{array}{l}\text { Bending moment resisted by SMA } \\
\text { reinforced sections }(\mathrm{kN} \cdot \mathrm{m})\end{array}$ & $\begin{array}{l}\text { Increment } \\
(\%)\end{array}$ \\
\hline 450.2 & 0.0 & 66.00 & 66.40 & -0.60 \\
\hline 450.2 & 0.1 & 109.97 & 107.59 & 2.21 \\
\hline 450.2 & 0.2 & 134.15 & 138.15 & -2.90 \\
\hline 450.2 & 0.3 & 158.30 & 152.6 & 3.74 \\
\hline 400.0 & 0.0 & 66.00 & 63.22 & 4.40 \\
\hline 400.0 & 0.1 & 109.97 & 104.58 & 5.15 \\
\hline 400.0 & 0.2 & 134.15 & 131.07 & 2.35 \\
\hline 400.0 & 0.3 & 158.30 & 150.07 & 5.48 \\
\hline
\end{tabular}

9. Plastic hinge length was longer in the specimens manufactured with HPC and grew with relative normal force $(v)$. No tendency was observed for tie spacing $\left(s_{t}\right)$.

The following conclusions are summarized from the parametric study results:

1. The maximum lateral load $\left(V_{\max }\right)$ was greater in the specimens manufactured with VHPC, increased with the longitudinal reinforcement ratio $\left(\rho_{l}\right)$, reduced with the length of the SMA Ni-Ti bars $\left(L_{S M A}\right)$, diminished with tie spacing $\left(s_{t}\right)$ and diminished with shear slenderness $\left(\lambda_{V}\right)$. As regards relative normal force, the maximum lateral load $\left(V_{\max }\right)$ grew while the compressive load capacity of the section was not exhausted, and reduced otherwise.

2. Displacement ductility $\left(\mu_{\Delta u}\right)$ increased with the longitudinal reinforcement ratio $\left(\rho_{l}\right)$ and the length of the SMA Ni-Ti bar $\left(L_{S M A}\right)$, and reduced with concrete strength, transverse reinforcement separation $\left(s_{t}\right)$, shear slenderness $\left(\lambda_{V}\right)$ and relative normal force $(v)$.

\section{Conflict of interest}

None.

\section{Acknowledgements}

This article forms part of the research carried out at the Concrete Science and Technology Institute (ICITECH) of the Universitat Politècnica de València (UPV). This work has been supported by the Spanish Ministry of Economy and Competitiveness through Project BIA2012-32645, and by the European Union through FEDER funds.
The authors thank the Spanish Ministry of Education, Culture and Sport for Grant FPU12/01451.

\section{References}

[1] E.M. de Fomento, E.C.P. del Hormigón, EHE-08: Instrucción de Hormigón Estructural: con comentarios de los miembros de la Comisión Permanente del Hormigón, Ministerio de Fomento, Secretaría General Técnica, 2008.

[2] Ministerio de Fomento, Norma de Construcción Sismorresistente: Puentes (NCSP-07), Centro de Publicaciones Secretaría General Técnica Ministerio de Fomento, España, 2007.

[3] EN 1998-1, Eurocode 8: Design of structures for earthquake resistance - Part 1: General rules, seismic actions and rules for buildings, 2004.

[4] Building Seismic Safety Council, NEHRP Recommended Seismic Provisions for New Buildings and Other Structures FEMA P-750, 2009.

[5] ACI Committee 318, ACI 318-14: Building Code Requirements for Structural Concrete and Commentary, 2014.

[6] ACI Committee 441, 441R-96: High Strength Concrete Columns 1996.

[7] L. Hsu, C.T. Hsu, Stress-strain behavior of steel-fiber high-strength concrete under compression, ACI Struct. J. 91 (1994) 448-457.

[8] S.J. Foster, On behavior of high-strength concrete columns: cover spalling, stee fibers, and ductility, ACI Struct. J. 98 (2001) 583-589.

[9] H. Aoude, W.D. Cook, D. Mitchell, Behavior of columns constructed with fibers and self-consolidating concrete, ACI Struct. J. 106 (2009) 349.

[10] G. Campione, M. Fossetti, M. Papia, Behavior of fiber-reinforced concrete columns under axially and eccentrically compressive loads, ACI Struct. J. 107 (2010) 272-281.

[11] P. Paultre, R. Eid, Y. Langlois, Y. Lévesque. Behavior of Steel Fiber-Reinforced High-Strength Concrete Columns under Uniaxial Compression Read More: http://ascelibrary.org/doi/abs/10.1061/\%28ASCE\%29ST.1943-541X.0000211. ASCE 2010, 136

[12] K.E. Caballero-Morrison, J.L. Bonet, J. Navarro-Gregori, J.R. Martí-Vargas Behaviour of steel-fibre-reinforced normal-strength concrete slende columns under cyclic loading, Eng. Struct. 39 (2012) 162-175, https://doi. org/10.1016/j.engstruct.2012.02.003.

[13] K.E. Caballero-Morrison, J.L. Bonet, J. Navarro-Gregori, P. Serna-Ros, An experimental study of steel fiber-reinforced high-strength concrete slender columns under cyclic loading, Eng. Struct. 57 (2013) 565-577, https://doi.org/ 10.1016/j.engstruct.2012.06.052. 
[14] M. del C. Castro Bugallo Análisis experimental de soportes de hormigón de altas prestaciones sometidos a compresión y carga lateral cíclica. Tesis Doctoral. Universitat Politècnica de València, 2015.

[15] A. Spasojevic, Structural implications of ultra-high performance fibrereinforced concrete in bridge design, 2008.

[16] E. Fehling, M. Schmidt, J. Walraven, T. Leutbecher, S. Fröhlich, Ultra-High Performance Concrete UHPC. Ultra-High Perform. Concr. UHPC, Wilhelm Ernst \& Sohn, Verlag für Architektur und technische Wissenschaften GmbH \& Co. KG; 2014, pp. 183-188.

[17] I.H. Yang, C. Joh, B.-S. Kim, Structural behavior of ultra high performance concrete beams subjected to bending, Eng. Struct. 32 (2010) 3478-3487, https://doi.org/10.1016/j.engstruct.2010.07.017.

[18] D.-Y. Yoo, Y.-S. Yoon, Structural performance of ultra-high-performance concrete beams with different steel fibers, Eng. Struct. 102 (2015) 409-423, https://doi.org/10.1016/j.engstruct.2015.08.029.

[19] P. Visintin, M.S. Mohamad Ali, T. Xie, A.B. Sturm, Experimental investigation of moment redistribution in ultra-high performance fibre reinforced concrete beams, Constr. Build. Mater. 166 (2018) 433-444, https://doi.org/10.1016/ j.conbuildmat.2018.01.156.

[20] J. Xia, T. Chan, K.R. Mackie, M.A. Saleem, A. Mirmiran, Sectional analysis for design of ultra-high performance fiber reinforced concrete beams with passive reinforcement, Eng. Struct. 160 (2018) 121-132, https://doi.org/10.1016/j. engstruct.2018.01.035.

[21] I.-H. Yang, C. Joh, J.W. Lee, B.-S. Kim, Torsional behavior of ultra-high performance concrete squared beams, Eng. Struct. 56 (2013) 372-383, https://doi.org/10.1016/j.engstruct.2013.05.027.

[22] A.P. Lampropoulos, S.A. Paschalis, O.T. Tsioulou, S.E. Dritsos, Strengthening of reinforced concrete beams using ultra high performance fibre reinforced concrete (UHPFRC), Eng. Struct. 106 (2016) 370-384, https://doi.org/10.1016/j. engstruct.2015.10.042.

[23] H.-O. Shin, K.-H. Min, D. Mitchell, Confinement of ultra-high-performance fiber reinforced concrete columns, Compos. Struct. 176 (2017) 124-142, https://doi, org/10.1016/j.compstruct.2017.05.022.

[24] H.-O. Shin, K.-H. Min, D. Mitchell, Uniaxial behavior of circular ultra-highperformance fiber-reinforced concrete columns confined by spiral reinforcement, Constr. Build. Mater. 168 (2018) 379-393, https://doi.org/ 10.1016/j.conbuildmat.2018.02.073.

[25] S. Xu, C. Wu, Z. Liu, K. Han, Y. Su, J. Zhao, et al., Experimental investigation of seismic behavior of ultra-high performance steel fiber reinforced concrete columns, Eng. Struct. 152 (2017) 129-148, https://doi.org/10.1016/j. engstruct.2017.09.007.

[26] B.-I. Bae, J.-H. Chung, H.-K. Choi, H.-S. Jung, C.-S. Choi, Experimental study on the cyclic behavior of steel fiber reinforced high strength concrete columns and evaluation of shear strength, Eng. Struct. 157 (2018) 250-267, https://doi. org/10.1016/j.engstruct.2017.11.072.

[27] M. Branco, L. Guerreiro, K.K. Mahesh, F.M. Braz Fernandes, Effect of load cycling on the phase transformations in $\mathrm{Ni}-\mathrm{Ti}$ wires for civil engineering applications, Constr. Build. Mater. 36 (2012) 508-519, https://doi.org/10.1016/ j.conbuildmat.2012.06.003.

[28] A. Cladera, B. Weber, C. Leinenbach, C. Czaderski, M. Shahverdi, M. Motavalli, Iron-based shape memory alloys for civil engineering structures: an overview, Constr. Build. Mater. 63 (2014) 281-293, https://doi.org/10.1016/ j.conbuildmat.2014.04.032.

[29] H. Fang, M.B. Wong, Y. Bai, R. Luo, Effect of heating/cooling rates on the material properties of NiTi wires for civil structural applications, Constr. Build. Mater. 101 (Part 1) (2015) 447-455, https://doi.org/10.1016/ j.conbuildmat.2015.10.081.

[30] Arup K. Maji, Negret Ihosvany, Smart prestressing with shape-memory alloy, J. Eng. Mech. 124 (1998) 1121-1128, https://doi.org/10.1061/(ASCE)0733-9399 (1998) 124:10(1121).

[31] M. Shahverdi, C. Czaderski, M. Motavalli, Iron-based shape memory alloys for prestressed near-surface mounted strengthening of reinforced concrete beams, Constr. Build. Mater. 112 (2016) 28-38, https://doi.org/10.1016/ j.conbuildmat.2016.02.174.

[32] C. Czaderski, M. Shahverdi, R. Brönnimann, C. Leinenbach, M. Motavalli, Feasibility of iron-based shape memory alloy strips for prestressed strengthening of concrete structures, Constr. Build. Mater. 56 (2014) 94-105 https://doi.org/10.1016/j.conbuildmat.2014.01.069.

[33] W.J. Lee, B. Weber, C. Leinenbach, Recovery stress formation in a restrained FeMn-Si-based shape memory alloy used for prestressing or mechanical joining, Constr. Build. Mater. 95 (2015) 600-610, https://doi.org/10.1016/ j.conbuildmat.2015.07.098.

[34] Eunsoo Choi, Sung-Chul Cho, Jong Wan Hu, Taehyo Park, Young-Soo Chung, Recovery and residual stress of SMA wires and applications for concrete structures, Smart Mater. Struct. 19 (2010) 094013.

[35] M. Shin, B. Andrawes, Experimental investigation of actively confined concrete using shape memory alloys, Eng. Struct. 32 (2010) 656-664, https://doi.org/ 10.1016/j.engstruct.2009.11.012.

[36] Q. Chen, M. Shin, B. Andrawes, Experimental study of non-circular concrete elements actively confined with shape memory alloy wires, Constr. Build. $\begin{array}{llll}\text { Mater. } & 61 & \text { (2014) 303-311, https://doi.org/10.1016/ }\end{array}$ j.conbuildmat.2014.02.076.

[37] Daghia Federica, Giammarruto Alessio, Pascale Giovanni, Combined use of FBG sensors and SMA actuators for concrete beams repair, Struct. Control Health. Monit. 18 (2010) 908-921, https://doi.org/10.1002/stc.410.
[38] A. Abdulridha, D. Palermo, S. Foo, F.J. Vecchio, Behavior and modeling of superelastic shape memory alloy reinforced concrete beams, Eng. Struct. 49 (2013) 893-904, https://doi.org/10.1016/j.engstruct.2012.12.041.

[39] S. Malagisi, S. Marfia, E. Sacco, J. Toti, Modeling of smart concrete beams with shape memory alloy actuators, Eng. Struct. 75 (2014) 63-72, https://doi.org/ 10.1016/j.engstruct.2014.05.035.

[40] M.S. Saiidi, M. Tazarv, B. Nakashoji, S. Varela, F. Kavianipour, Resilient and sustainable bridges of the future, Int. J. Bridge Eng. IJBE 3 (2015) 37-48.

[41] J.L. Bonet, J. Pereiro-Barceló, A. Navarro-Gómez. Elemento de Conexión de Protección Contra Sismos. P201631022, 2017.

[42] M.S. Alam, M. Moni, S. Tesfamariam, Seismic overstrength and ductility of concrete buildings reinforced with superelastic shape memory alloy rebar, Eng. Struct. 34 (2012) 8-20, https://doi.org/10.1016/j.engstruct.2011.08.030.

[43] A.H.M.M. Billah, M. Shahria Alam, Plastic hinge length of shape memory alloy (SMA) reinforced concrete bridge pier, Eng. Struct. 117 (2016) 321-331, https://doi.org/10.1016/j.engstruct.2016.02.050.

[44] A.H.M.M. Billah, M.S. Alam, Probabilistic seismic risk assessment of concrete bridge piers reinforced with different types of shape memory alloys, Eng. Struct. 162 (2018) 97-108, https://doi.org/10.1016/j.engstruct.2018.02.034.

[45] A.H.M. Muntasir Billah, M. Shahria Alam, Seismic performance of concrete columns reinforced with hybrid shape memory alloy (SMA) and fiber reinforced polymer (FRP) bars, Constr. Build. Mater. 28 (2012) 730-742, https://doi.org/10.1016/j.conbuildmat.2011.10.020.

[46] C. Qiu, S. Zhu, Characterization of cyclic properties of superelastic monocrystalline $\mathrm{Cu}-\mathrm{Al}-\mathrm{Be} \mathrm{SMA}$ wires for seismic applications, Constr. Build.

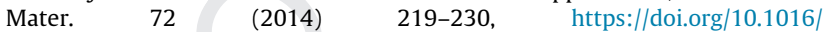
j.conbuildmat.2014.08.065.

[47] M.J.N. Priestley, R. Park, Strength and ductility of concrete bridge columns under seismic loading, Struct. J. 84 (1987). doi: 10.14359/2800.

[48] A.C. Barrera, J.L. Bonet, M.L. Romero, P.F. Miguel, Experimental tests of slender reinforced concrete columns under combined axial load and lateral force, Eng. Struct. 33 (2011) 3676-3689, https://doi.org/10.1016/j.engstruct.2011.08.003.

[49] A.C. Barrera, J.L. Bonet, M.L. Romero, M.A. Fernández, Ductility of slender reinforced concrete columns under monotonic flexure and constant axial load, Eng. Struct. 40 (2012) 398-412, https://doi.org/10.1016/j. engstruct.2012.03.012.

[50] J. Pereiro-Barceló, J.L. Bonet, Mixed model for the analytical determination of critical buckling load of passive reinforcement in compressed RC and FRC elements under monotonic loading, Eng. Struct. 150 (2017) 76-90, https://doi. org/10.1016/j.engstruct.2017.07.026.

[51] J. Pereiro-Barceló, J.L. Bonet, J.R. Albiol-Ibáñez, Buckling of steel and Ni-Ti reinforcements in very high performance concrete (VHPC) elements, Constr. Build. Mater. 160 (2018) 551-563, https://doi.org/10.1016/ j.conbuildmat.2017.11.113.

[52] AENOR. Spanish Association for Standards and Certification. UNE-EN 123903:2009. Testing hardened concrete - Part 3: Compressive strength of test specimens 2009 .

[53] AENOR. Spanish Association for Standards and Certification. UNE-EN 14651:2007. Test method for metallic fibre concrete - Measuring the flexural tensile strength (limit of proportionality (LOP), residual) 2017.

[54] AENOR. Spanish Association for Standards and Certification. UNE-EN ISO 68921:2017. Metallic materials. Tensile testing. Part 1: Method of test at ambient temperature. 2002.

[55] ASTM F2004 - 05. Standard Test Method for Transformation Temperature of Nickel-Titanium Alloys by Thermal Analysisoja.pdf, 2010.

[56] ACI Committee 318. ACI 374.1-05: Acceptance Criteria for Moment Frames Based on Structural Testing and Commentary, 2005.

[57] FEMA. Recommended seismic design criteria for new moment-frame buildings, 2000.

[58] Federal Emergency Management Agency. NEHRP Recommended Seismic Provisions for New Buildings and Other Structures FEMA P-750. Washington, DC, 2009.

[59] P. Paultre, F. Legeron, D. Mongeau, Influence of concrete strength and transverse reinforcement yield strength on behavior of high-strength concrete columns, Struct. J. 98 (2001). doi: 10.14359/10292.

[60] H.J. Pam, J.C.M. Ho, Length of critical region for confinement steel in limited ductility high-strength reinforced concrete columns, Eng. Struct. 31 (2009) 2896-2908, https://doi.org/10.1016/j.engstruct.2009.07.015.

[61] W. Zhu, J. Jia, J. Gao, F. Zhang, Experimental study on steel reinforced highstrength concrete columns under cyclic lateral force and constant axial load, Eng. Struct. 125 (2016) 191-204, https://doi.org/10.1016/j. engstruct.2016.07.018.

[62] Y.L. Mo, J. Chan, Bond and slip of plain rebars in concrete, J. Mater. Civ. Eng. 8 (1996) 208-211.

[63] G.M. Verderame, Carlo G De, P. Ricci, G. Fabbrocino, Cyclic bond behaviour of plain bars. Part II: Analytical investigation, Constr. Build. Mater. 23 (2009) 3512-3522, https://doi.org/10.1016/j.conbuildmat.2009.07.001.

[64] M. Tazarv, M. Saiid Saiidi, Low-damage precast columns for accelerated bridge construction in high seismic zones, J. Bridge Eng. 21 (2016) 04015056, https:// doi.org/10.1061/(ASCE)BE.1943-5592.0000806.

[65] McKenna F, Fenves GL, Filippou FC. OpenSees. University of California, Berkeley: n.d.

[66] M. Menegotto, P.E. Pinto, Method of Analysis for Cyclically Loaded RC Frames Including Changes in Geometry and Non-elastic Behaviour of Elements Under Combined Normal Force and Bending. IABSE Congr Rep Work Comm 1973, 13. 
[67] F.C. Filippou, E.P. Popov, V.V. Bertero, Modeling of reinforced concrete joints under cyclic excitations, J. Struct. Eng. ASCE (1983) 109.

[68] C. Christopoulos, R. Tremblay, H.-J. Kim, M. Lacerte, Self-centering energy dissipative bracing system for the seismic resistance of structures: development and validation, J. Struct. Eng. 134 (2008) 96-107, https://doi. org/10.1061/(ASCE)0733-9445(2008) 134:1(96).

[69] T.-S. Han, P.H. Feenstra, S.L. Billington, Simulation of highly ductile fiberreinforced cement-based composite components under cyclic loading, Struct. J. 100 (2003) 749-757.
[70] SETRA/AFGC, Bétons fibrés à ultra-hautes performances/Ultra High Performance Fibre-Reinforced Concretes. Association Francaise de Génie Civil, 2013.

[71] D. Cusson, P. Paultre, Stress-strain model for confined high-strength concrete, J. Struct. Eng.-ASCE 121 (1995) 468-477, https://doi.org/10.1061/(ASCE)07339445(1995) 121:3(468).

[72] EN 1992-1-1, Eurocode 2: Design of concrete structures - Part 1-1: General rules and rules for buildings, 2004 